\title{
The Enthalpies of Combustion and Formation of the Mono-chlorobenzoic Acids
}

\author{
Walter H. Johnson and Edward J. Prosen \\ Institute for Materials Research, National Bureau of Standards, Washington, D.C. 20234
}

(May 30, 1974)

\begin{abstract}
The enthalpies of combustion of $o_{-}^{-}, m$-, and $p$-chlorobenzoic acid have been determined in an adiabatic rotating-bomb calorimeter. The enthalpies of formation have been obtained by combination of the experimental data with the accepted values for the enthalpies of formation of water, carbon dioxide, and aqueous hydrochloric acid. The results of other investigators are discussed briefly. The resulting values and their estimated 95 percent confidence limits are as follows:

$o$-Chlorobenzoic acid $m$-Chlorobenzoic acid o-Chlorobenzoic acid

$\begin{array}{lrcc}\Delta H c^{\circ}\left(25{ }^{\circ} \mathrm{C}\right) & -3087.91 \pm 0.69 \mathrm{~kJ} / \mathrm{mol} & -3068.05 \pm 1.53 \mathrm{~kJ} / \mathrm{mol} & -3064.40 \pm 0.66 \mathrm{~kJ} / \mathrm{mol} \\ \Delta H f^{\circ}\left(25{ }^{\circ} \mathrm{C}\right) & -404.83 \pm 0.74 \mathrm{~kJ} / \mathrm{mol} & -424.59 \pm 1.55 \mathrm{~kJ} / \mathrm{mol} & -428.16 \pm 0.72 \mathrm{~kJ} / \mathrm{mol} . \\ \text { Where } \Delta H c^{\circ} \text { corresponds to the process: } & -424.37 & -429.94 \\ & -404.61 & \mathrm{C}_{7} \mathrm{H}_{5} \mathrm{O}_{2} \mathrm{Cl}(\mathrm{c})+7 \mathrm{O}_{2}(\mathrm{~g})+198 \mathrm{H}_{2} \mathrm{O}(\mathrm{liq}) \rightarrow 7 \mathrm{CO}_{2}(\mathrm{~g})+\left[\mathrm{HCl}+200 \mathrm{H}_{2} \mathrm{O}\right](\mathrm{liq}) .\end{array}$
\end{abstract}

Key words: Combustion; enthalpy; formation; heat; isomerization; secondary standard.

\section{Introduction}

The use of benzoic acid as a calorific standard for the calibration of oxygen-bomb calorimeters is well known. While other compounds have been proposed, benzoic acid is and will probably continue to be the internationally recognized primary standard. The techniques used with it may be applied without question to the combustion of other similar organic compounds. However, when the compound being studied contains elements other than carbon, hydrogen, and oxygen, certain special techniques may be required in order to obtain accurate values. The most convenient method by which the accuracy of calorimetric measurements on a certain class of compounds can be verified is by comparison with the results obtained when using a secondary standard that contains the same elements. The use of a secondary standard is for the verification of the chemistry of the combustion process and the accuracy of the energy corrections involved in the reduction of the data. The effective energy equivalent of the calorimeter system must be determined either by means of electrical energy or by means of a primary standard. Chlorobenzoic acid has been proposed as a secondary standard for the thermochemistry of chlorine-containing compounds. This material appears to have the desired characteristics of a standard substance as to (1) stability, (2) low vapor pressure, (3) non-hygroscopicity, (4) ease of handling, (5) ease of ignition, and (6) ca- pability of complete combustion without the use of an auxiliary substance. When compounds containing $\mathrm{Cl}, \mathrm{Br}$, or I are burned in an oxygen bomb a significant portion of the free halogen together with the halogen acid is found among the combustion products. The relative proportions of free halogen are not strictly reproducible for a given calorimeter system and vary greatly between different systems. In order to obtain reliable values it is necessary to use a reducing agent to convert all free halogen to the corresponding halogen acid. An aqueous solution of arsenious oxide is an excellent reducing agent for this purpose.

This investigation was undertaken to establish the suitability of chlorobenzoic acid as a secondary standard, to study the techniques required in order to obtain reliable values, and to examine the relative merits of the isomeric monochlorobenzoic acids.

\section{Materials}

\section{o-Chlorobenzoic acid}

This sample was purified at the NBS as a possible micro-analytical standard but because of the small quantity available it was never issued as a standard reference material. The purity was estimated to be 99.99 mol percent from melting point determinations. Titration of the carboxyl with standard alkali gave the purity as $100.00 \mathrm{wt}$ percent in terms of benzoic acid, Standard Reference Material (SRM) 39i. Analyses of 
the combustion products indicated a purity of $99.90 \mathrm{wt}$ percent on the basis of $\mathrm{CO}_{2}$.

\section{$m$-Chlorobenzoic acid}

This material was obtained from the J. T. Baker Chemical Company as an "ultrex" sample. It was labeled by Baker as : Comm. No. 4976, UHC 318, Titration of the carboxyl gave a purity of $99.82 \mathrm{wt}$ percent in terms of benzoic acid SRM 39i.

\section{p-Chlorobenzoic acid}

This sample was obtained from the Thermochemical Laboratory of the University of Lund, Sweden, through the courtesy of Margret Månsson. Titration with standard alkali gave a purity of $99.97 \mathrm{wt}$ percent in terms of benzoic acid, SRM 39i. Analyses of the combustion products gave a purity of 99.95 wt percent on the basis of carbon dioxide.

\section{Arsenious oxide}

The arsenious oxide was Standard Reference Material No. 83b. This material was used to prepare the aqueous solution for the chlorobenzoic acid combustion experiments and also for the standardization of the potassium permanaganate solution used in the potentiometric titrations of the bomb solutions.

\section{Oxygen}

The oxygen was obtained from the Matheson Company as Ultra-Pure-Oxygen. A certificate of analysis furnished with the cylinder gave the major impurities in ppm as: $\mathrm{Kr}, 12.0 ; \mathrm{N}_{2}, 3.0 ; \mathrm{Xe}, 0.7 ; \mathrm{N}_{2} \mathrm{O}, 0.8$.

\section{Potassium permanganate solution}

Approximately $3.2 \mathrm{~g}$ of reagent grade potassium permanganate was dissolved in 1 liter of distilled water, the solution was heated to boiling, kept hot for an hour, allowed to stand for two days, then filtered and stored in an amber-glass bottle. Portions of arsenious oxide, SRM 83b, were weighed, dissolved in $5 \mathrm{~cm}^{3}$ of 1 normal alkali, acidified with $5 \mathrm{~cm}^{3}$ of $6-N$ hydrochloric acid, diluted to $30 \mathrm{~cm}^{3}$, a drop of $0.002 \mathrm{M}$ potassium iodate added and titrated with the permanganate solution. The end point was determined potentiometrically using platinum and calomel electrodes; the endpoint was extremely sharp and a precision of 0.1 percent was easily obtained. One $\mathrm{cm}^{3}$ of the solution was equivalent to $24.67 \mu \mathrm{mol}$ of $\mathrm{As}_{2} \mathrm{O}_{3}$.

\section{Arsenious oxide solution}

Approximately $15 \mathrm{~g}$ of arsenious oxide, SRM 83b, was placed in a flask with $500 \mathrm{~cm}^{3}$ of water, heated to boiling then set aside for several days. The solution was filtered into a bottle containing $50 \mathrm{~cm}^{3}$ of water and the concentration of $\mathrm{As}_{2} \mathrm{O}_{3}$ determined by titration with permanganate using the same procedure as for standardization of the permanganate solution. The concentration was adjusted to $0.05 \mathrm{M}$ by further dilution.

\section{Calorimetric Apparatus}

The adiabatic vacuum-jacketed, aneroid calorimeter, the platinum-lined combustion bomb, and the temperature measurement systems were the same as described [1] ${ }^{1}$ except for a loosely fitting polyethylene cup placed in the bottom of the bomb cavity. The density of the polyethylene was determined to be 0.918 $\mathrm{g} \cdot \mathrm{cm}^{-3}$ and the weight of the cup was $1.959 \mathrm{~g}$ from which the volume was calculated to be $2.14 \mathrm{~cm}^{3}$. The effective volume of the empty bomb (but including the cup) is $96 \mathrm{~cm}^{3}$. Temperatures were determined by means of a $25-\Omega$ platinum resistance thermometer (capsule type) from the ratio of the potential drop across the thermometer to that across a standard resistor which was connected in series with the thermometer.

\footnotetext{
' Figures in brackets indicate the literature references at the end of this paper.
}

\section{Proceduts}

For each experiment the sample was pressed into a pellet, weighed into a platinum crucible and placed in the bomb such that the sample was in contact with a 2-cm length of $0.075-\mathrm{mm}$ diam platinum wire which was attached to the bomb electrodes. The air density at the time of weighing was determined from measurements of temperature, pressure and relative humidity. By means of a micro-buret, $3.000 \mathrm{~cm}^{3}$ of an arsenious oxide solution was introduced into a polyethylene dish on the base of the bomb. An equal portion was placed in a weighed polyethylene bottle, diluted to about $100 \mathrm{~cm}^{3}$, capped tightly and set aside as a reference. The bomb was then sealed, flushed with $1000 \mathrm{~cm}^{3}$ of oxygen and filled to $31.62 \mathrm{~atm}$. The bomb was placed in the calorimeter, the filling temperature was observed, the calorimeter jacket was evacuated and the adiabatic temperature controls placed in operation. The bomb was heated electrically to approximately $24.99{ }^{\circ} \mathrm{C}$, and the system left overnight with the pumps and the adiabatic temperature controls in operation. While this initial equilibration period was much longer than required, it was necessary to begin observations early in the day in order to complete the calorimetric experiment, to perform the analyses of the combustion products, and to prepare for the next experiment during the working day.

On the following morning, calorimeter temperatures were observed at intervals of a few minutes during an initial rating period of about $45 \mathrm{~min}$. Because of the heating effect of the electric current through the platinum resistance thermometer there was a steady increase in temperature of approximately $0.001{ }^{\circ} \mathrm{C} / \mathrm{h}$. The sample was ignited by discharging an 18,000 $\mu \mathrm{F}$ condenser, previously charged to $24 \mathrm{~V}$, through the platinum wire fuse; the initial and final voltages across the condenser were recorded. The bonb was then rotated to wash the inner surface with the arsenious oxide solution. After about 20 min thermal equilibrium was approached and calorimeter temperatures were observed at intervals of a few minutes during a 40 -min final rating period. 
The bomb was then removed from the calorimeter and the gaseous contents slowly released. In order to reduce the time of contact of the solution with the platinum inner surface of the bomb, no analyses of the gaseous combustion products were made for the calorimetric combustion experiments. The bomb was then opened and the contents transferred to a weighed polyethylene bottle; care was taken to insure that the transfer was quantitative and that no contact with the solution was made by anything other than platinum and polyethylene. The volume of the final bomb solution together with the washings was usually about $50 \mathrm{~cm}^{3}$; it was then diluted to approximately $100 \mathrm{~cm}^{3}$ and tightly capped.

\section{Analysis for arsenic (III)}

Weighed aliquots, approximately $10 \mathrm{~g}$ each, of the initial and final solutions were acidified with $5 \mathrm{~cm}^{3}$ of 6- $N$ hydrochloric acid, a drop of $0.0025 M$ potassium iodate was added to each and the solutions titrated potentiometrically with standard potassium permanganate solution using a micro-buret. Duplicate determinations were made in all cases with a precision of about \pm 0.1 percent.

The concentrations of $\mathrm{As}^{3+}$ in a few of the bomb solutions were redetermined after standing for about one month; no significant change in concentration was observed.

\section{Determination of nitric acid}

Another aliquot was taken and the quantity of nitric acid determined by a modified micro-Kjeldahl procedure [2]. The modification consisted of substituting an infra-red lamp for the heating element. This determination was much less precise than the arsenious acid analyses. Duplicate measurements differed by more than 10 percent, and the variation between the duplicate measurements was about equal to that between the experiments. For this reason the mean of a series of determinations was taken and this value was used for all experiments.

\section{Determination of combined platinum}

Chemically combined platinum in the bomb solution was determined by a colorimetric procedure [3] involving the rose-colored complex formed by the addition of potassium iodide to a dilute solution of chloroplatinic acid. A standard platinum solution was prepared by dissolving a weighed quantity of platinum in hot concentrated hydrochloric acid in the presence of chlorine. In order to ensure that the platinum and arsenic were in their fully oxidized states, an excess of chlorine water and $200 \mathrm{mg}$ of sodium chloride were added to a $10 \mathrm{~g}$ aliquot of the bomb washing and the solution was evaporated to dryness without boiling. The dry residue, free from acid fumes was dissolved in water forming a clear solution. A freshly prepared solution of potassium iodide in aqueous hydrochloric acid and additional water was added to give $12 \mathrm{~g}$ of solution for the optical measurement which was 0.025
$M$ with respect to hydrochloric acid and contained 0.1 weight-percent of potassium iodide.

After a color development of at least four hours in darkness, optical absorbances were obtained using a spectrophotometer. A blank and standard, latinim solutions containing amounts of arsenious oxide and hydrochloric acid similar to the bomb solution were carried through the procedure simultaneously. With consideration for the probable errors in preparing and dispensing the standard platinum solution and in the determination of the optical absorbance an error of \pm 1 microgram of platinum is assigned for each determination which leads to an uncertainty of \pm 5 percent in the energy of decomposition of chloroplatinic acid.

In a preliminary series of experiments it was discovered that the quantity of oxidation of arsenious oxide appeared to be a function of the time during which the solution remained in the bomb. The fact that small amounts of oxidation do occur has been known for some time [4,9], in this particular investigation, however, the problem was more serious because of the length of time involved.

Attempts to reduce the effect by treatment of the platinum surface of the bomb were not successful. Then, a series of tests were made in an attempt to determine a correction based upon exposure time. The results of these tests are given in table 1 , in which

TABLE 1. Changes in As(III) in bomb solution in contact with bomb walls

\begin{tabular}{|c|c|c|c|c|}
\hline $\begin{array}{c}\mathrm{As}_{2} \mathrm{O}_{3}(\mathrm{i}) \\
\mu \mathrm{mol}\end{array}$ & $\begin{array}{c}\mathrm{As}_{2} \mathrm{O}_{3}(\mathrm{f}) \\
\mu \mathrm{mol}\end{array}$ & $\underset{\mathrm{h}}{\text { Duration }}$ & $\begin{array}{c}\text { Rate } \\
\mu \mathrm{mol} / \mathrm{h}\end{array}$ & Comment \\
\hline 200.35 & 192.96 & 18.7 & 0.40 & \\
\hline 317.73 & 296.89 & 41.7 & .49 & \\
\hline 212.33 & 207.99 & 19.5 & .22 & (1) \\
\hline 150.30 & 137.82 & 21 & .59 & (2) \\
\hline 178.72 & 172.26 & 3 & 2.15 & (3) \\
\hline 217.08 & 179.93 & 18 & 2.06 & (4) \\
\hline 150.01 & 118.40 & 22 & 1.44 & (5) \\
\hline 277.31 & 206.03 & 24 & 2.97 & (6) \\
\hline 151.07 & 141.81 & 66 & 0.14 & (7) \\
\hline 378.50 & 303.49 & 64 & 1.17 & (8) \\
\hline 234.12 & 228.50 & 11.5 & 0.49 & (9) \\
\hline 178.79 & 173.54 & 18 & .29 & (10) \\
\hline 144.58 & 126.94 & 22 & .80 & (11) \\
\hline 154.22 & 151.15 & 2.5 & 1.23 & (11) \\
\hline 210.16 & 207.77 & 1.5 & 1.59 & (12) \\
\hline 172.43 & 162.51 & 16 & 0.62 & (12) \\
\hline 234.99 & 231.57 & 5 & .68 & (12) \\
\hline 101.40 & 90.83 & 22 & .48 & (13) \\
\hline 101.52 & 91.00 & 23 & .46 & (13) \\
\hline 101.65 & 85.25 & 19.25 & .85 & (13) \\
\hline 203.84 & 181.07 & 11.75 & 1.94 & (13) \\
\hline 150.61 & 133.75 & 48 & 0.35 & (14) \\
\hline 150.61 & 131.06 & 71 & .28 & (15) \\
\hline 201.11 & 193.74 & 18.7 & .39 & (16) \\
\hline 149.97 & 149.10 & 0.42 & 2.07 & (17) \\
\hline 149.97 & 149.72 & .32 & 0.78 & (17) \\
\hline 149.97 & 149.82 & .33 & .46 & (17) \\
\hline
\end{tabular}

1. Platinum surface polished with fine steel wool, washed with $6 \mathrm{~N} \mathrm{HCl}$ then with water.

2. Platinum surface polished with steel wool, washed with aqua regia then with water.

3. Platinum surface washed with $10 \mathrm{~N} \mathrm{NaOH}$, then $6 \mathrm{~N} \mathrm{HCl}$ and finally with water. 
4. Fired charge of benzoic acid then washed bomb with water.

5. Platinum surface leached with $3 N \mathrm{HCl}$ for $100 \mathrm{~h}$ then washed with water.

6. Platinum surface leached with $\mathrm{As}_{2} \mathrm{O}_{3}$ soln for $48 \mathrm{~h}$ then washed with $1 N \mathrm{NaOH}, 6 N \mathrm{HCl}$, and water.

7. Platinum surface polished with rouge, washed with alcohol and water.

8. Platinum surface buffed with rouge.

9. Platinum polished with rouge, washed with $6 \mathrm{~N} \mathrm{HCl}, 48$ percent $\mathrm{HF}$, and water.

10. Platinum surface leached with $\mathrm{H}_{2} \mathrm{SO}_{4}, \mathrm{H}_{2} \mathrm{O}$, hot $\mathrm{As}_{2} \mathrm{O}_{3}$ soln, then polished and leached with $6 \mathrm{~N} \mathrm{HCl}$.

11. Platinum surface washed with soap, hot $\mathrm{As}_{2} \mathrm{O}_{3}$, alcohol and ether.

12. Bomb pressure 40 atm $\mathrm{O}_{2}$.

13. Platinum surface polished with rouge on felt, washed with $6 \mathrm{~N}$ $\mathrm{HCl}$ and water.

14. $0.1 \mathrm{~cm}^{3} 0.1 \mathrm{~N} \mathrm{HCl}$ added to $\mathrm{As}_{2} \mathrm{O}_{3}$ soln.

15. $0.1 \mathrm{~cm}^{3} 6 \mathrm{~N} \mathrm{HCl}$ added to $\mathrm{As}_{2} \mathrm{O}_{3}$ soln.

16. $0.1 \mathrm{~cm}^{3} 0.1 \mathrm{~N} \mathrm{NaOH}$ added to $\mathrm{As}_{2} \mathrm{O}_{3}$ soln.

17. $0.1 \mathrm{~g}$ benzoic acid burned in bomb.

are listed initial and final amounts of $\mathrm{As}_{2} \mathrm{O}_{3}$, the elapsed time, average rate of oxidation of $\mathrm{As}_{2} \mathrm{O}_{3}$, and comments on the experiments. Examination of these data indicates that there is no reliable correlation with time of exposure.

The results obtained when the solution was separated from the bomb surface and when helium is used instead of oxygen are given in table 2. The results show that where an extended period of time elapses between the time of filling and the time of ignition, the error in the amount of oxidation of arsenious oxide can be greatly reduced by placing the bomb solution in a container which prevents direct contact with platinum prior to ignition of the sample.

The placing of the arsenious oxide solution in the polyethylene dish, however, obviously does not completely eliminate the error in the determination of the quantity actually oxidized during the calorimetric experiment. This is in part due to the length of time the solutions remain in the bomb during the final rating period. During this interval any postcombustion reaction that is occurring will form part of the rating-period energy changes. In order to arrive at a correction for the quantity oxidized after the combustion reaction we determined the quantity oxidized
TABLE 2. Changes in As(III) in bomb solution separated from bomb walls

\begin{tabular}{c|c|c|c|c}
\hline \hline $\mathrm{As}_{2} \mathrm{O}_{3}(\mathrm{i})$ & $\mathrm{As}_{2} \mathrm{O}_{3}(\mathrm{f})$ & Duration & Rate & Comment \\
\hline$\mu \mathrm{mol}$ & $\mu \mathrm{mol}$ & $\mathrm{h}$ & $\mu \mathrm{mol} / \mathrm{h}$ & \\
\hline 216.05 & 217.24 & 66.5 & -0.02 & $(1)$ \\
369.28 & 369.05 & 45.5 & .004 & $(2)$ \\
512.46 & 512.23 & 67.5 & .003 & $(2)$ \\
369.28 & 369.03 & 21.5 & .012 & $(3)$ \\
512.46 & 512.02 & 66.5 & .007 & $(4)$ \\
101.45 & 85.03 & 24 & .68 & $(5)$ \\
102.06 & 88.4 & 22 & .62 & $(6)$ \\
146.36 & 141.27 & 17.5 & .29 & $(7)$ \\
146.39 & 131.17 & 17.5 & .87 & $(7)$ \\
146.34 & 146.19 & 17 & .009 & $(8)$ \\
146.66 & 146.64 & 1 & .02 & $(8)$ \\
147.36 & 141.10 & 89 & .07 & $(9)$ \\
\hline
\end{tabular}

1. $\mathrm{As}_{2} \mathrm{O}_{3}$ solution in glass vial, $30 \mathrm{~atm}$ of oxygen.

2. Helium at $3 \mathrm{~atm}, \mathrm{As}_{2} \mathrm{O}_{3}$ solution in contact with platinum surface.

3. Helium at 15 atm, $\mathrm{As}_{2} \mathrm{O}_{3}$ solution in contact with platinum surface.

4. Helium at $40 \mathrm{~atm}, \mathrm{As}_{2} \mathrm{O}_{3}$ solution in contact with platinum surface.

5. $\mathrm{As}_{2} \mathrm{O}_{3}$ soln in $\mathrm{Pt}$ crucible, 30 atm of oxygen.

6. $\mathrm{As}_{2} \mathrm{O}_{3}$ soln in $\mathrm{Pt}$ crucible in glass vial, 30 atm of oxygen.

7. Base of bomb coated with silicone grease, $\mathrm{As}_{2} \mathrm{O}_{3}$ solution in contact with the grease, 30 atm oxygen.

8. $\mathrm{As}_{2} \mathrm{O}_{3}$ soln in polyethylene cup, $30 \mathrm{~atm}$ of oxygen.

9. $\mathrm{As}_{2} \mathrm{O}_{3}$ soln in $\mathrm{Pt}$ crucible, $30 \mathrm{~atm}$ of oxygen.

in experiments using benzoic acid.

In two such experiments, performed in the same manner as with the chlorobenzoic acid, the quantities of $\mathrm{As}_{2} \mathrm{O}_{5}$ were determined to be 1.67 and $1.22 \mu \mathrm{mol}$, respectively. The average of these values, $1.45 \mu$ mole, was subtracted from the observed quantities of $\mathrm{As}_{2} \mathrm{O}_{5}$ in all of the chlorobenzoic acid experiments. The error introduced by the variability of this correction is of the order of $30 \mathrm{ppm}$ in $\Delta U_{c}^{\circ}$.

\section{Results and calculations}

The results of the benzoic acid calibration experiments are given in table 3 . All calculations were per-

TABLE 3. Calibration experiments with benzoic acid

\begin{tabular}{|c|c|c|c|c|c|c|}
\hline Expt. No. & 306 & 307 & 309 & 324 & 326 & 327 \\
\hline 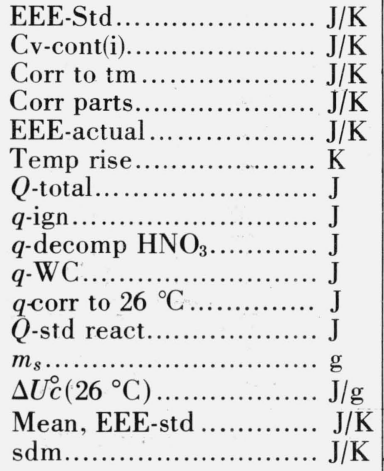 & $\begin{array}{c}2518.57 \\
4.47 \\
0.06 \\
.00 \\
2523.10 \\
1.067945 \\
-2694.53 \\
0.96 \\
.24 \\
1.99 \\
0.00 \\
-2691.34 \\
0.101897 \\
-26412.52 \\
2518.84 \\
0.11\end{array}$ & $\begin{array}{c}2518.92 \\
4.46 \\
0.04 \\
.00 \\
2523.41 \\
1.030450 \\
-2600.25 \\
0.93 \\
.15 \\
1.92 \\
0.00 \\
-2597.26 \\
0.098334 \\
-26412.52\end{array}$ & $\begin{array}{c}2518.46 \\
4.46 \\
0.04 \\
.00 \\
2522.96 \\
1.047503 \\
-2642.81 \\
1.12 \\
0.14 \\
1.95 \\
0.00 \\
-2639.60 \\
0.099938 \\
-26412.52\end{array}$ & $\begin{array}{c}2518.98 \\
4.47 \\
0.08 \\
-.13 \\
2523.40 \\
1.084511 \\
-2736.65 \\
0.86 \\
.22 \\
2.02 \\
0.00 \\
-2733.55 \\
0.103495 \\
-26412.52\end{array}$ & $\begin{array}{c}2519.07 \\
4.47 \\
0.09 \\
-.13 \\
2523.50 \\
1.096805 \\
-2767.79 \\
0.78 \\
.27 \\
2.04 \\
0.01 \\
-2764.69 \\
0.104674 \\
-26412.52\end{array}$ & $\begin{array}{c}2519.03 \\
4.47 \\
0.09 \\
-.13 \\
2523.46 \\
1.085546 \\
-2739.33 \\
0.71 \\
.30 \\
2.02 \\
0.01 \\
-2736.29 \\
0.103599 \\
-26412.52\end{array}$ \\
\hline
\end{tabular}


formed by computer using a program developed by M. Månsson. ${ }^{3}$ The terms used are defined as follows : EEE-std, the effective energy equivalent of the standard empty calorimeter including the polyethylene cup and the bomb with all internal platinum parts except the crucible.

Cv-cont(i), the heat capacity at constant volume of the crucible, sample, bomb solution, and oxygen.

Corr to tm, a correction to EEE-std for the deviation from $25.5^{\circ} \mathrm{C}$ of the actual mean temperature of the experiment.

Corr-parts, a correction to EEE-std for known changes to the system during the series of experiments.

EEE-actual, the effective energy equivalent of the actual calorimeter.

Temp. rise, the observed increase in temperature for the over-all bomb process.

$Q$-total, the total quantity of energy evolved for the bomb process, obtained as the product of the effective energy requirement of the calorimeter and the temperature rise.

$q$-ign, the electrical energy introduced to ignite the sample.

$q$-decomp $\mathrm{HNO}_{3}$, the calculated quantity of energy required to decompose the actual amount of nitric acid found in the bomb to gaseous nitrogen, gaseous oxygen and liquid water. The molar value used in calculating this was $59.7 \mathrm{~kJ} / \mathrm{mol} \mathrm{HNO}_{3}$.

$q$-oxid $\mathrm{As}_{2} \mathrm{O}_{3}$, the quantity of energy evolved by oxidation of $\mathrm{As}_{2} \mathrm{O}_{3}$ to $\mathrm{As}_{2} \mathrm{O}_{5}$.

$q$-decomp $\mathrm{H}_{2} \mathrm{PtCl}_{6}$, the quantity of energy required to decompose the chloroplatinic acid into platinum and aqueous hydrochloric acid.

$q$-WC, the Washburn correction applied to convert all reactants and products to their respective thermodynamic standard states at the actual final temperature.

$q$-corr to $26{ }^{\circ} \mathrm{C}$, the correction of the energy of the isothermal bomb process from the actual final temperature to $26^{\circ} \mathrm{C}$.
$Q$-std react, the energy evolved by the isotherma] bomb reaction.

$m_{s}$, the mass of sample.

$\Delta U_{c}^{\circ}\left(26^{\circ} \mathrm{C}\right)$, the internal energy change resulting from the isothermal bomb reaction at $26^{\circ}{ }^{\circ} \mathrm{C}$ in $\mathrm{J} / \mathrm{g}$.

The densities, heat capacities, and compressibility coefficients were assumed to be the same for the three isomeric chlorobenzoic acids.

The values used in calculation of the data are as follows:

\begin{tabular}{l|c|c|c}
\hline \hline & Density & $C_{p}$ & $\left(\frac{\partial V}{\partial T}\right)_{p}$ \\
\hline & $\mathrm{g} \cdot \mathrm{cm}^{-3}$ & $\mathrm{Jg}^{-1} \cdot \mathrm{K}^{-1}$ & $\mathrm{~cm}^{3} \cdot \mathrm{g}^{-1} \cdot$ \\
$\mathrm{K}^{-1}$ \\
Benzoic acid & 1.320 & 1.21 & 0.00441 \\
Monochlorobenzoic acid & 1.541 & 0.93 & .000227 \\
\hline
\end{tabular}

The energy of decomposition of aqueous $\mathrm{As}_{2} \mathrm{O}_{5}$ to aqueous $\mathrm{As}_{2} \mathrm{O}_{3}$ was taken as $\Delta U=-319.95 \mathrm{~kJ} / \mathrm{mol}$ from the data of Sunner and Thoren [5]. The other auxiliary data were taken from Wagman, et al., NBS Technical Notes 270-3 and 270-4 [6] and from Parker, INSRDS-NBS 2 [7].

The results of the experiments on the $o-, m-$, and $p$-chlorobenzoic acids are given in tables 4,5 , and 6 , respectively.

The values in the tables have been rounded from the computer printout and therefore the values for EEEactual and $Q$-std react may differ slightly from those obtained by summation of the tabulated items, which are less exact.

In the calibration experiments, EEE-std is calculated by an iterative procedure from the mass of sample. The certified calorific value for benzoic acid, SRM 39i, is given as $26434 \mathrm{~J} / \mathrm{g}$ under certificate conditions at $25^{\circ} \mathrm{C}$; from this we obtain $\Delta U c^{\cup}\left(26^{\circ} \mathrm{C}\right)=-26412.35$ $\mathrm{J} / \mathrm{g}$ for the isothermal bomb process at $26{ }^{\circ} \mathrm{C}$.

TABLE 4. Calorimetric experiments on o-chlorobenzoic acid

\begin{tabular}{|c|c|c|c|c|c|c|}
\hline Expt. No. & 339 & 340 & 341 & 342 & 343 & 344 \\
\hline 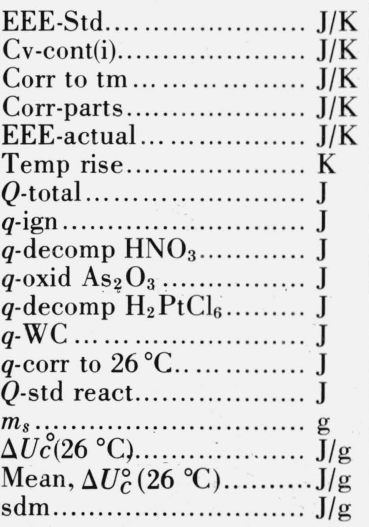 & $\begin{array}{c}2518.84 \\
15.56 \\
0.00 \\
-.13 \\
2534.27 \\
1.007860 \\
-2554.19 \\
0.86 \\
.23 \\
11.94 \\
0.17 \\
3.91 \\
0.00 \\
-2537.08 \\
0.128651 \\
-19720.64 \\
-19721.32 \\
1.62\end{array}$ & $\begin{array}{c}2518.84 \\
15.56 \\
0.00 \\
-.13 \\
2534.27 \\
1.001101 \\
-2537.06 \\
0.76 \\
.23 \\
11.75 \\
0.24 \\
3.88 \\
0.00 \\
-2520.21 \\
0.127767 \\
-19725.05\end{array}$ & $\begin{array}{c}2518.84 \\
15.56 \\
0.05 \\
-.13 \\
2534.33 \\
1.036651 \\
-2627.21 \\
0.85 \\
.23 \\
12.45 \\
0.26 \\
1.02 \\
0.01 \\
-2609.40 \\
0.132317 \\
-19720.82\end{array}$ & $\begin{array}{c}2518.84 \\
15.56 \\
0.05 \\
-.13 \\
2534.32 \\
1.031816 \\
-2614.95 \\
0.81 \\
.23 \\
12.47 \\
0.24 \\
4.10 \\
0.00 \\
-2597.20 \\
0.131716 \\
-19718.18\end{array}$ & $\begin{array}{c}2518.84 \\
15.56 \\
0.04 \\
-.13 \\
2534.31 \\
1.033357 \\
-2618.86 \\
0.90 \\
.23 \\
12.38 \\
0.22 \\
4.00 \\
0.00 \\
-2601.12 \\
0.131857 \\
-19726.82\end{array}$ & $\begin{array}{c}2518.84 \\
15.56 \\
0.02 \\
-.13 \\
2534.29 \\
1.030524 \\
-2611.65 \\
0.88 \\
.23 \\
12.30 \\
0.23 \\
4.00 \\
0.00 \\
-2594.00 \\
0.131566 \\
-19716.39\end{array}$ \\
\hline
\end{tabular}

${ }^{3}$ Appropriate changes in a computer program, originally developed by L. Bjellerup for bromine compounds, [13] were made by M. Månsson of the University of Lund, Sweden. 
TABLE 5. Calorimetric experiments on m-chlorobenzoic acid

\begin{tabular}{|c|c|c|c|c|c|}
\hline Expt. No. & 316 & 317 & 318 & 319 & 320 \\
\hline
\end{tabular}

TABLE 6. Calorimetric experiments on p-chlorobenzoic acid

\begin{tabular}{|c|c|c|c|c|c|c|c|c|}
\hline Expt. No. & 330 & 331 & 332 & 334 & 335 & 336 & 337 & 338 \\
\hline 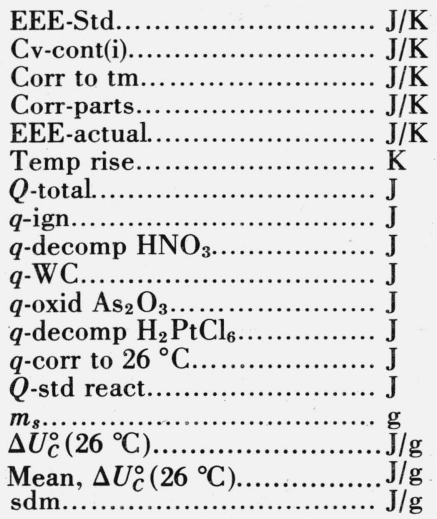 & $\begin{array}{c}2518.84 \\
15.60 \\
-0.05 \\
-.13 \\
2534.26 \\
0.957365 \\
-2426.21 \\
0.86 \\
.23 \\
3.74 \\
12.32 \\
0.09 \\
.00 \\
-2408.97 \\
0.123099 \\
-19569.37 \\
-19572.32 \\
1.54\end{array}$ & $\begin{array}{c}2518.84 \\
15.60 \\
0.05 \\
-.13 \\
2534.37 \\
1.045164 \\
-2648.83 \\
0.86 \\
.23 \\
4.09 \\
13.84 \\
0.18 \\
.00 \\
-2629.63 \\
0.134397 \\
-19566.15\end{array}$ & $\begin{array}{c}2518.84 \\
15.58 \\
0.01 \\
-.13 \\
2534.30 \\
1.012769 \\
-2566.66 \\
0.76 \\
.23 \\
3.97 \\
12.24 \\
0.08 \\
.00 \\
-2549.38 \\
0.130283 \\
-19568.02\end{array}$ & $\begin{array}{c}2518.84 \\
15.63 \\
-0.01 \\
-.13 \\
2534.33 \\
1.008331 \\
-2555.45 \\
0.91 \\
.23 \\
3.94 \\
12.17 \\
0.19 \\
.00 \\
-2538.01 \\
0.129646 \\
-19576.46\end{array}$ & $\begin{array}{c}2518.84 \\
15.63 \\
0.02 \\
-.13 \\
2534.37 \\
1.019058 \\
-2582.66 \\
0.83 \\
.23 \\
3.98 \\
12.45 \\
0.18 \\
.00 \\
-2565.00 \\
0.131007 \\
-19579.11\end{array}$ & $\begin{array}{c}2518.84 \\
15.57 \\
0.04 \\
-.13 \\
2534.32 \\
1.014268 \\
-2570.48 \\
0.56 \\
.23 \\
3.96 \\
12.80 \\
0.09 \\
.00 \\
-2552.84 \\
0.130427 \\
-19572.94\end{array}$ & $\begin{array}{c}2518.84 \\
15.57 \\
-0.01 \\
-.39 \\
2534.02 \\
1.019202 \\
-2582.67 \\
0.89 \\
.23 \\
3.99 \\
11.86 \\
0.16 \\
.00 \\
-2565.55 \\
0.131073 \\
-19573.44\end{array}$ & $\begin{array}{c}2518.84 \\
15.57 \\
0.02 \\
-.13 \\
2534.30 \\
1.019970 \\
-2584.91 \\
0.96 \\
.23 \\
3.99 \\
11.96 \\
0.17 \\
.00 \\
-2567.60 \\
0.131180 \\
-19573.11\end{array}$ \\
\hline
\end{tabular}


The values given for $\Delta U_{C}^{\circ}\left(26^{\circ} \mathrm{C}\right)$ correspond to the process

$$
\begin{aligned}
\mathrm{C}_{7} \mathrm{H}_{5} \mathrm{O}_{2} \mathrm{Cl}(\mathrm{c})+7 \mathrm{O}_{2}(\mathrm{~g})+198 \mathrm{H}_{2} \mathrm{O}(\mathrm{l}) & \rightarrow 7 \mathrm{CO}_{2}(\mathrm{~g}) \\
+ & {\left[\mathrm{HCl}+200 \mathrm{H}_{2} \mathrm{O}\right](\mathrm{l}) }
\end{aligned}
$$

The values for $\Delta H_{C}^{\circ}\left(26^{\circ} \mathrm{C}\right), \Delta H_{C}^{\circ}\left(25^{\circ} \mathrm{C}\right), \Delta H^{\circ} f\left(25^{\circ} \mathrm{C}\right)$ derived from the experiments are summarized in table 7 for the three isomeric acids together with their uncertainties.

TABLE 7 Summary of thermodynamic results

\begin{tabular}{l|c|r|r}
\hline & $\begin{array}{c}\text { Orthochlorobenzoic } \\
\text { acid }\end{array}$ & $\begin{array}{c}\text { Metachlorobenzoic } \\
\text { acid }\end{array}$ & $\begin{array}{c}\text { Parachlorobenzoic } \\
\text { acid }\end{array}$ \\
\hline$\Delta U^{\circ} c\left(26^{\circ} \mathrm{C}\right) \ldots \ldots \ldots . . . \mathrm{J} / \mathrm{g}$ & $-19721.32 \pm 4.30$ & $-19595.10 \pm 9.80$ & $-19572.32 \pm 4.36$ \\
$\Delta U^{\circ} c\left(26^{\circ} \mathrm{C}\right) \ldots \ldots \ldots \mathrm{kJ} / \mathrm{mol}$ & $-3087.73 \pm 0.69$ & $-3067.99 \pm 1.53$ & $-3064.40 \pm 0.66$ \\
$\Delta H^{\circ} c\left(26^{\circ} \mathrm{C}\right) \ldots \ldots \ldots . \mathrm{kJ} / \mathrm{mol}$ & $-3087.73 \pm 0.69$ & $-3067.47 \pm 1.53$ & $-3064.40 \pm 0.66$ \\
$\Delta H^{\circ} c\left(25^{\circ} \mathrm{C}\right) \ldots \ldots \ldots . \mathrm{kJ} / \mathrm{mol}$ & $-3087.91 \pm 0.69$ & $-3068.15 \pm 1.53$ & $-3064.58 \pm 0.66$ \\
$\Delta H f^{\circ}\left(25^{\circ} \mathrm{C}\right) \ldots \ldots \ldots . \mathrm{kJ} / \mathrm{mol}$ & $-404.61 \pm 0.75$ & $-424.37 \pm 1.56$ & $-427.94 \pm 0.72$ \\
\hline
\end{tabular}

The uncertainties for $\Delta U_{c}^{\circ}$ and $\Delta H_{c}^{\circ}$ have been obtained by combination of $2 \mathrm{sdm}$ for the calibration experiments with $2 \mathrm{sdm}$ for the reaction experiments together with 0.01 percent for uncertainty in the certified value used for benzoic acid, and with reasonable estimates of all other known sources of error. The uncertainty in $\Delta H f^{\circ}$ was obtained by combination of the uncertainty in $\Delta H_{C}^{\circ}$ with 0.01 percent in the values taken for the heats of formation of $\mathrm{CO}_{2}(\mathrm{~g}), \mathrm{H}_{2} \mathrm{O}$ (liq), and $\mathrm{HCl}(\mathrm{aq})$.

\section{Comparison With Other Investigations}

The only previously reported values for the enthalpies of combustion of ortho- and metachlorobenzoic acid were performed by Karlsson [8] and later corrected by Smith, Bjellerup, Krook, and Westermark [9]. Several measurements of the enthalpy of combustion of $p$-chlorobenzoic acid have been reported. A comparison of the results obtained in the various investigations is given for $\Delta H_{C}^{\circ}\left(25{ }^{\circ} \mathrm{C}\right)$ in $\mathrm{kJ} / \mathrm{mol}$ for the reaction:

$\mathrm{C}_{7} \mathrm{H}_{5} \mathrm{O}_{2} \mathrm{Cl}(\mathrm{c})+7 \mathrm{O}_{2}(\mathrm{~g})+598 \mathrm{H}_{2} \mathrm{O}($ liq $) \rightarrow 7 \mathrm{CO}_{2}(\mathrm{~g})+$

$\left[\mathrm{HCl} \cdot 600 \mathrm{H}_{2} \mathrm{O}\right](\mathrm{liq})$

\begin{tabular}{c|c|l|l}
\hline ortho & meta & \multicolumn{2}{|c}{ para } \\
\hline$-3094.1 \pm 8.0$ & $-3069.4 \pm 8.0$ & $-3066.6 \pm 8.0$ & {$[8,9]$} \\
& & $-3065.62 \pm 1.67$ & {$[10]$} \\
& & $-3064.78 \pm 3.14$ & {$[11]$} \\
& & $-3062.98 \pm 0.75$ & {$[12]$} \\
$-3088.02 \pm 0.69$ & $-3068.26 \pm 1.56$ & $-3062.77 \pm 1.05$ & {$[12]$} \\
& & $-3064.94 \pm 0.84$ & {$[12]$} \\
& & & This \\
& & & investiga- \\
& & & \\
\hline
\end{tabular}

The authors wish to thank M. Månsson for providing the sample, the computer program for reduction of the data and for many helpful suggestions in the analyses of the combustion products. We are also indebted to $\mathrm{R}$. Schumm of this laboratory for performing the chloroplatinic acid determinations.

This investigation was supported in part by the Office of Standard Reference Materials of the National Bureau of Standards.

\section{References}

[1] Prosen, E. J., and Johnson, W.H., in prep. For a partial description see G. T. Armstrong and W. H. Johnson, National Bureau of Standards Report NBSIR 73-158, July 1973.

[2] Kieselbach, R., Ind. and Eng. Chem. 16, 764 (1944).

[3] Sandell, E. B., Calorimetric Determination of Traces of Metals, Interscience, New York, 1944, p. 361.

[4] Berthelot, M., and Matignon, C., Ann. chim. et phys. [6] 23, 509 (1891).

[5] Sunner, S., and Thoren, S. A., Acta Chem. Scand. 18, 1528 (1964).

[6] Wagman, D. D., Evans, W. H., Parker, V. B., Halow, 1., Bailey, S. M., and Schumm, R. H., Selected values of chemical thermodynamic properties, Nat. Bur. Stand. (U.S.), Tech. Note 270-3, 268 pages (Jan. 1968); Tech. Note 270-5, 49 pages (Mar. 1971).

[7] Parker, V. B., Thermal properties of aqueous uni-valent electrolytes, NSRDS-NBS 2 (April 1965), U.S. Government Printing Office, Washington, DC 20402.

[8] Karlsson, K. J., Zur Thermochemie einiger chlor' und jodhaltiger Benzolderivat, Dissertation, Lund, Sweden, 1941.

[9] Smith, L., Bjellerup, L., Krook, S., and Westermark, H., Acta Chem. Scand. 7, 65(1953).

[10] Bjellerup, L. and Smith, L., Kgl. Fysiograph., Sallskap, Lund Forh. 24, 21 (1954).

[11] Hajiev, S. N., and Agarunov, M. J., J. Organomet. Chem., $11,415(1968)$

[12] Hu, A. T., Sinke, G. C., Månsson, M., and Ringner, B., J. Chem. Thermodynamics 4, (2), 283 (1972).

[13] Bjellerup, L., Acta Chem. Scand. 14, 617 (1960).

(Paper 78A6-841) 



\title{
Publications of the National Bureau of Standards*
}

\author{
Citations with Selected Abstracts
}

J. Res. Nat. Bur. Stand. (U.S.), 78A(Phys. and Chem.), No. 5 (Sept.Aug. 1974), SD Catalog No. C13.22/sec.A:78/5.

Spectrum of doubly ionized praseodymium from $2107 \AA$ to $10716 \AA$, J. Sugar.

A heat-loss-compenstated calorimeter: Theory, design, and performance, S. R. Domen and P. J. Lamperti.

The enthalpies of combustion and formation of linear polyethylene, P. L. Splitstone and W. H. Johnson.

High pressure measurements of density, velocity of sound, and bulk moduli of pentane and 2 -methylbutane and their mixtures, J. C. Houck.

Long-time creep in a pure-gum rubber vulcanizate: Influence of humidity and atmospheric oxygen, L. A. Wood, G. W. Bullman, and F. L. Roth.

Adaptation of a high-accuracy spectrophotometer for ultraviolet work, K. D. Mielenz, R. Mavrodineanu, and E. D. Cehelnik.

J. Res. Nat. Bur. Stand. (U.S.), 78B (Math. Sci.), No. 3 (July-Sept. 1974), SD Catalog No. C13.22/sec.B:78/3.

A sufficient condition for matrix stability, C. R. Johnson.

Computation of the field of values of a $2 \times 2$ matrix, $C$. $R$. Johnson.

The factorization of a matrix as the commutator of two matrices, J. M. Smith.

Complete elliptic integrals resulting from infinite integrals of Bessel functions, S. Okui.

The convex hull of the transposition matrices, L. S. Joel.

Computational experience with an algorithm for finding the $k$ shortest paths in a network, D. R. Shier.

How bad is the Hadamard determinantal bound?, C. R. Johnson and M. Newman.

Monogr. 138. MeV total neutron cross sections, R. B. Schwartz, R. A. Schrack, and H. T. Heaton II, Nat. Bur. Stand. (U.S.), Monogr. 138, 160 pages (Jan. 1974) SD Catalog No. C13.44:138, $\$ 3.60$.

Key words: $\mathrm{MeV}$ neutrons; neutron time-of-flight; neutron total cross sections.

This report is a compilation of the $\mathrm{MeV}$ neutron total cross section data measured at the National Bureau of Standards over the past several years. The measurements generally span the energy interval from 0.5 to 15 or $20 \mathrm{MeV}$; data are presented in graphical form for twelve normally occurring elements, plus the separated isotopes ${ }^{235} \mathrm{U}$, ${ }^{238} \mathrm{U}$, and ${ }^{239} \mathrm{Pu}$. An appendix is included which gives complete details of the experimental technique.

*Publications with prices and SD Catalog numbers may be purchased'directly from the Superintendent of Documents, U.S. Government Printing Office, Washington, D.C. 20402 (foreign: onefourth additional). Microfiche copies are available from the National Technical Information Service (NTIS), Springfield, Va. 22151. Reprints from outside journals and the NBS Journal of Research may often be obtained directly from the authors.
Monogr. 141. The measurement of lumped parameter impedance: A metrology guide, R. N. Jones, Nat. Bur. Stand. (U.S.), Monogr. 141, 211 pages (June 1974) SD Catalog No. C13.44:141, $\$ 5.50$.

Key words: adapters; capacitance; capacitors; detectors; generators; impedance instruments; impedance standards; inductance; inductors; measurement methods; reactance; resistance; resistor; standards.

The measurement of two-terminal impedance in the $30 \mathrm{kHz}$ to 300 $\mathrm{MHz}$ range involves a variety of different methods including null, resonance, active and comparison. Each method is represented by a number of instruments having specific capabilities, strengths, and weaknesses. This metrology guide is intended to assist the scientist who is not intimately familiar with impedance measurement, in the selection and use of the best instrument for a particular requirement. Information is included on range and accuracy capabilities as well as availability and éase of operation. In addition to providing help in the selection of the appropriate instrument, there are operating tips which enhance accuracy, criteria for choosing standards, means for extending normal measurement range of an instrument, a discussion on generators and detectors, and a section on the evaluation and use of adapters. Finally, an extensive bibliography is included to assist in pursuing a particular problem beyond the depth of the guide.

Monogr. 142. The measurement of noise performance factors: A metrology guide, M. G. Arthur, Nat. Bur. Stand. (U.S.), Monogr. 142, 202 pages (June 1974) SD Catalog No. C13.44:142, $\$ 5.45$.

Key words: effective input noise temperature; measurement errors; noise factor; noise measurements; noise performance factors; noise temperature; Y-factor measurements.

This metrology guide provides the basis for critical comparisons among seven measurement techniques for average noise factor and effective input noise temperature. The techniques that are described, discussed, and analyzed include the (1) Y-Factor, (2) 3-dB, (3) Automatic, (4) Gain Control, (5) CW, (6) Tangential, and (7) Comparison Techniques. The analyses yield working equations and error equations by which accuracy capabilities are compared. Each technique is also analyzed for (a) frequency range for best measurement results, (b) special instrumentation requirements, (c) speed and convenience, (d) operator skill required, and (e) special measurement problems. General instrumentation requirements and practical measurement problems are discussed for the benefit of the nonexpert metrologist. Worked examples illustrate the principles involved in applying the working and error equations. An extensive bibliography and suggested reading list aid the metrologist to locate additional material on these measurements. Taken altogether, this guide will be helpful in selecting the best measurement technique for any of a wide range of operational requirements and, once the technique is selected, it will be of further benefit in helping the metrologist identify where his efforts should be placed to derive the greatest efficiency and accuracy from his measurement system. 
SP395. Simulation and gaming. Proceedings of the 12th Annual Symposium National Gaming Council and the 4th Annual Conference International Simulation and Gaming Association, held at the National Bureau of Standards, Gaithersburg, Md., September 17-19, 1973, J. E. Moriarty, Ed., Nat. Bur. Stand. (U.S.), Spec. Publ. 395, 458 pages (June 1974) SD Catalog No. C13.10:395, \$4.25.

Key words: computer; decision-making; games; learning; manual games; simulation.

This document contains the proceedings of a Gaming Conference along with many formal papers assembled to provide a comprehensive collection of up-to-date gaming information. The proceedings are divided into three major sections, namely, Theory and Evaluation, Design and Applications. Each section contains the text of informal workshops held during the Conference and a selection of formal papers. There is a significant amount of reference material cited in the formal papers along with timely questions and challenges explored and amplified in the workshops.

\section{SP400-6. Semiconductor measurement technology:}

Microelectronic test patterns: An overview, M. G. Buehler, Nat. Bur. Stand. (U.S.), Spec. Publ. 400-6, 24 pages (Aug. 1974) SD Catalog No. C13.10:400-6, 60 cents.

Key words: integrated circuits; microelectronic test patterns.

The test patterns considered are those designed by the physical electronics engineer to evaluate fabrication processes rather than those designed by the microcircuit designer. The evaluation of fabrication processes can reveal if a process is under control and can indicate the stability and reliability of the resulting microcircuit. This evaluation is in essence an evaluation of a microcircuit's material characteristics, for process control and reliability depend ultimately on the right atoms being in the right places.

Various material analysis test structures are described, such as resistors, MOS capacitors, and gated $p-n$ junctions along with the material parameters that can be derived from each. These test structures are illustrated by the NBS- 2 test pattern, and its use in process control is described. Examples are given which span the range from those structures which are amenable to production testing to those which require an advanced measurement capability. In addition test structures are discussed with regard to their usability; this encompasses their size, sensitivity, correlation, contacting schemes, testability, and packaging. Test structures must be properly designed so that desired parameters are measured. In this regard various design aspects such as metal taps and diffused taps are mentioned. Finally the role of NBS in evaluating and designing test patterns is discussed.

NSRDS-NBS47. Tables of collision integrals and second virial coefficients for the $(\mathrm{m}, 6,8)$ intermolecular potential function, M. Klein, H. J. M. Hanley, F. J. Smith, and P. Holland, Nat. Stand. Ref. Data Ser., Nat. Bur. Stand. (U.S.), 47, 157 pages (June 1974) SD Catalog No. C. 3.48:47, $\$ 1.90$.

Key words: collision integrals; diffusion; potential; thermal conductivity; thermal diffusion; transport properties; viscosity.

Tables of collision integrals and second virial coefficients are presented for the $(m, 6,8)$ potential function. Ten values of the repulsive exponent $\mathrm{m}$ are included which range in unit steps from $\mathrm{m}=9$ through $\mathrm{m}=18$. Approximately 6 values of the parameter, $\gamma$, associated with the inverse eighth power term, are included for each value of $\mathrm{m}$. These tables are equivalent, therefore, to tables for 60 three-parameter $(\mathrm{m}, 6)$ potential functions. Comparisons of our results for $m=12$ and $\gamma=0$ (corresponding to the $(12,6)$ function) have been made with other calculations. Based on these comparisons, the accuracy of the present calculation appears to be at least two or three parts in 10,000 depending on the temperature. A table is included which contains the Boyle temperature, the Boyle volume, and the ratio of the intermolecular separation at the potential minimum to the separation at the zero of the potential.
NSRDS-NBS52. Electronic absorption and internal and external vibrational data of atomic and molecular ions doped in alkali halide crystals, S. C. Jain, A. V. R. Warrier, and S. K. Agarwal, Nat. Stand. Ref. Data. Ser., Nat. Bur. Stand. (U.S.), 52, 59 pages (July 1974) SD Catalog No. C13.48:52, 95 cents.

Key words: atomic ions; doped alkali halide crystals; external vibrational modes; internal vibrational modes; molecular ions.

Spectral data for more than 70 atomic and molecularions doped in alkali halide crystals are tabulated. The tables include electronic absorption data, listings of internal vibrational frequencies of doped complex ions, and tabulations of the frequencies of external modes. The data that appear in the tables were selected on the basis of the consistency among different authors, the types of instruments, and the temperature of measurement. In addition to the data, the tables include the spectroscopic assignments given by the authors in the references cited.

BSS50. Weather resistance of porcelain enamels - 15-year inspection of the 1956 exposure test, M. A. Baker, Nat. Bur. Stand. (U.S.), Bldg. Sci. Ser. 50, 15 pages (July 1974) SD Catalog No. C13.29/2:50, 55 cents.

Key words: acid resistance; color; gloss; $\mathrm{pH}$; porcelain enamel; relative humidity; weather resistance.

In 1956, and exposure test of porcelain enamels at 4 urban and 2 ocean shore sites in the continental United States was initiated by the National Bureau of Standards and the Porcelain Enamel Institute. After 15 years, all exposed specimens were returned to the Bureau and the changes in gloss and color determined. The gloss changes were found to be significantly different at all exposure sites except Pittsburgh, Los Angeles and Dallas. The most severe changes occurred at the Kure Beach, N.C. site nearest the ocean, while the least changes occurred at Pittsburgh, Los Angeles and Dallas. The differences in behavior of the specimens correlated with both the average relative humidity and the $\mathrm{pH}$ of the suspended particulate matter at the different sites.

A correlation appeared to exist between the acid resistance of the enamels and changes in gloss and color. The regular, glossy, acid-resistant enamels on steel showed the best weather resistance of the various types tested.

Comparison with enamel specimens exposed for 15 years in an earlier test showed that porcelain enamels produced in the early 1950 's were equally resistant to changes in gloss and color as those produced in the late 1930's.

FIPS PUB 8-4. Standard Metropolitan Statistical Areas, H. E. McEwen, Standards Coordinator, Nat. Bur. Stand. (U.S.), Fed. Info. Process. Stand. Publ. (FIPS PUB) 8-4, 20 pages (1974) SD Catalog No. C13.52:8-4, 60 cents.

Key words: computers; data processing; Federal Information Processing Standards Publication; representations and codes; Standard Metropolitan Statistical Areas.

This publication provides standard identifications and codes for representing Standard Metropolitan Statistical Areas for the interchange of machine sensible data among agencies. It supersedes FIPS 8-3, Standard Metropolitan Statistical Areas, dated 1973 August 15. The general concept of a Standard Metropolitan Statistical Area, commonly referred to as "SMSA" is one of an integrated economic and social unit with a recognized large population nucleus. The codes are available on Hollerith punched cards. The following data elements are provided: SMSA Title (Name) and SMSA Code. Supersedes FIPS PUB 8-3.

FIPS PUB 30. Software summary for describing computer programs and automated data systems, B. Marron, Standards Coordinator, Nat. Bur. Stand. (U.S.), Fed. Info. Process. Stand. Publ. (FIPS PUB) 30, 5 pages (1974) SD Catalog No. C13.52:30, 20 cents. 
Key words: computer programs; computers; computer software; data processing; Federal Information Processing Standards; information processing.

This publication provides a standard software summary form (SF185) together with instructions for describing computer programs and/or automated data systems for identification, reference, and dissemination purposes. Federal Information Processing Standard Software Summary Form (SF-185) will be used in documenting summaries or abstracts of programs and/or automated data systems that are developed or acquired by Federal departments and agencies. This form will also be used by the General Services Administration in the establishment of a centralized registry of selected government software

PS57-73. Cellulosic fiber insulating board. (ANS A194.1-1973),

K. G. Newell, Jr., Technical Standards Coordinator, Nat. Bur. Stand. (U.S.), Prod. Stand. 57-73, 8 pages (Nov. 1973) SD Catalog No. C13.20/2:57-73, 40 cents.

Key words: board, cellulosic fiber insulating; cellulosic fiber insulating board; fiber, cellulosic insulating board; insulating, cellulosic fiber board

This Voluntary Product Standard covers requirements and applicable methods of test for the composition, construction, dimensions, moisture content, and physical properties of cellulosic fiber insulating board. Methods of identifying products which comply with this standard are included and information concerning surface finishes and edge details is given in appendix A. Supersedes CS42-49 and R179-63.

PS58-73. Basic hardboard. (ANS A135.4-1973), K. G. Newell, Jr.

Technical Standards Coordinator, Nat. Bur. Stand. (U.S.), Prod. Stand. 58-73, 6 pages (June 1974) SD Catalog No. C13.20/2:58-73, 40 cents.

Key words: basic hardboard; hardboard.

This Voluntary Product Standard covers requirements and methods of test for water resistance, modulus of rupture, tensile strength, surface finish, dimensions, squareness, edge straightness, and moisture content of five classes of basic hardboard. Methods of identifying hardboard that conforms to the standard are provided. Supersedes CS251-63.

TN653. The thermophysical properties of methane, from 90 to $500 \mathrm{~K}$ at pressures to $700 \mathrm{bar}, \mathrm{R}$. D. Goodwin, Nat. Bur. Stand. (U.S.), Tech. Note 653, 280 pages (Apr. 1974) SD Catalog No. C13.46:653, $\$ 2.25$.

Key words: densities; enthalpies; entropies; equation of state; internal energies; isobars; isochores; isotherms; Joule-Thomson inversion; latent heats of vaporization; melting line; orthobaric densities; PVT data; specific heats; speeds of sound; vapor pressures.

Thermophysical properties of methane are tabulated at uniform temperatures from 90.68 to $500 \mathrm{~K}$ along isobars to $700 \mathrm{bar}$. A novel equation of state is employed for the first time, having origin on the vapor-liquid coexistence boundary. Computations are based almost entirely on ideal gas specific heats and experimental P- $\rho$-T data via the equation of state, without weighting to data for derived properties. Good agreement with such data confirms validity of the equation and method. New P- $\rho$-T data are reported at 0.3 to 1.7 times the critical density.

TN654. Electromagnetic noise in Robena No. 4 coal mine, W. D. Bensema, M. Kanda, and J. W. Adams, Nat. Bur. Stand. (U.S.), Tech. Note 654, 194 pages (Apr. 1974) SD Catalog No. C13.46:654, $\$ 1.50$.

Key words: amplitude probability distribution; coal mine noise; digital data; electromagnetic interference; electromagnetic noise; emergency communications; Fast Fourier Transform
Gaussian distribution; impulsive noise; magnetic field strength; measurement instrumentation; spectral density; time-dependent spectral density.

Two different techniques were used to make measurements of the absolute value of electromagnetic noise in an operating coal mine, Robena No. 4, located near Waynesburg, Pa. One technique measures noise over the entire electromagnetic spectrum of interest for brief time periods. With present instrumentation, the spectrum can be covered from $40 \mathrm{~Hz}$ to $400 \mathrm{kHz}$. It is recorded using broad-band analog magnetic tape, and the noise data are later transformed to give spectral plots. The other technique records noise envelopes at several discrete frequencies for a sufficient amount of time to provide amplitude probability distributions.

The specific measured results are given in a number of spectral plots and amplitude probability distribution plots. The general results are that at frequencies below $10 \mathrm{kHz}$, power line noise within the mine is severe. Impulsive noise is severe near arcing trolleys, and at lower frequencies near any transmission line. Carrier trolley phone signals and harmonics are strong throughout the mine whenever the trolley phone is in operation.

Additional information beyond that included in this report may be obtained from the authors, who are with the Electromagnetics Division of the National Bureau of Standards.

TN829. Multicommodity network plotting via program NETPLT, Z. G. Ruthberg, G. R. Bolotsky, and W. Slater, Jr., Nat. Bur. Stand. (U.S.), Tech. Note 829, 67 pages (June 1974) SD Catalog No. C13.46:829, \$1.10.

Key words: communication network; multicommodity network; network; network display; plotting algorithm; plotting program.

In the design and operation of complex networks, it is often an advantage to obtain a visual representation that readily allows for a quick appraisal of the network's current configuration or of its changed appearance due to variations of its nodes and links. The program NETPLT enables a user to plot the two leading characteristics of any multicommodity network: (1) nodes and links and (2) the multiple source-sink structure (multi-commodity property). The unique feature of NETPLT is its unambiguous planar representation of links. NETPLT uses an arc of a circle instead of the usual straight line, to represent a connector between a node pair (link).

TN833. Fire department ground ladders-results of a preliminary study, H. P. Utech, Nat. Bur. Stand. (U.S.), Tech. Note 833, 82 pages (July 1974) SD Catalog No. C13.46:833, \$1.20.

Key words: aluminum; fire department; ladders; performance requirements; standards.

The key performance requirements for fire department ground ladders were determined. Existing ladder standards were reviewed and found to be unnecessarily restrictive in some areas and inadequate and unrealistic in others. Included in the report are metallurgical studies of three ladders that failed in service as well as a correlation of hardness with tensile and yield strength for 6061-T6 alloy.

TN837. Barrier penetration tests, R. T. Moore, Nat. Bur. Stand. (U.S.), Tech. Note 837, 191 pages (June 1974) SD Catalog No. C13.46:837, $\$ 2.15$.

Key words: barrier penetration; intrusion detection; intrusion resistance; physical security.

Sixteen structural barrier panels were tested to determine their resistance to forcible penetration through the use of readily available tooling. Thirteen of these represented experimental techniques to reinforce an existing structural barrier of low penetration resistance; the other three were designs which would be most appropriate to consider as replacement barriers. Minimum man-passable sized openings were made in the barriers in working times which averaged 7.85 minutes and ranged from 1.52 to 25.56 minutes. One of the 
replacement and two of the reinforcing designs showed superior costeffectiveness.

Seven woven, wire-mesh security fence specimens were also tested for their intrusion deterrence capability. The test results indicate that the deterrrent influence of unelectrified fences of the type tested is largely psychological rather than physical. All of the specimens could be penetrated in 0.14 minutes or less.

Samples of the acoustical and vibrational data produced during the penetration tests add to the growing body of data which are expected to be useful in the design and selection of electronic intrusion alarm equipments.

TN839. Fire detection: The state-of-the-art, R. L. P. Custer and R. G. Bright, Nat. Bur. Stand. (U.S.), Tech. Note 839, 119 pages (June 1974) SD Catalog No. C13.46:839, \$1.55

Key words: fire detection; fire detection code requirements; fire detector testing and standards; fire detectors; fire signatures.

The current state-of-the-art in fire detection technology is reviewed considering the nature of fire signatures, detection modes used, test methods, performance requirements and code requirements for fire detection. Present trends in standards development and recommendations for future work are included. An extensive bibliography is provided.

TN840. Reference materials for collaborative tests of air quality methods, R. H. Johns and J. K. Taylor, Nat. Bur. Stand. (U.S.), Tech. Note 840, 17 pages (Aug. 1974) SD Catalog No. C.13.46:840, 55 cents.

Key words: air pollution; chemical analysis; Standard Reference Materials.

Reference materials and associated distribution apparatus were developed for seven ambient air contaminants and for two smokestack contaminants. These established the reference base for collaborative tests of ASTM procedures for ambient air quality and smokestack emissions carried out under a three-year program known as Project Threshold.

TN841. Review of reverberant sound power measurement standard and recommendations for further research, Nat. Bur. Stand. (U.S.), Tech. Note 841, 24 pages (Aug. 1974) SD Catalog No. C13.46:841, 60 cents.

Key words: acoustics; noise; reverberation room; sound power; statistical room acoustics.

This report presents a critical review of American National Standard Sl.21-1972, "Methods for the Determination of Sound Power Levels of Small Sources in Reverberation Rooms." This standard, as now embodied, represents a major advance in the state-of-the-art of reverberation room measurement of sound power. This report was prepared in order to identify additional analytical and experimental information needed for further refinement of this standard. This report presents a detailed critique of specific items in the standard. Indications are given of both general research areas for statistical room acoustics and of specific research areas for improved reverberant room sound power measurements.

TN842. Concepts in quality software design, S. L. Stewart, Ed., Nat. Bur. Stand. (U.S.), Tech. Note 842, 89 pages (Aug. 1974) SD Catalog No. C13.46:842, $\$ 1.25$.

Key words: control structures; GOTO-less programming; program validation; programming; proofs of correctness; referential transparency; software quality; structured programming; topdown programming.

A seminar series on quality software, sponsored by the Systems and Software Division, was held at the National Bureau of Standards during the summer of 1972. This Note includes five of these seminars in edited form. (I) A brief background provides motivation for studies in software quality. The authors mention some factors which influence software manufacture, and propose measures which might quantify concepts of "software quality." Several approaches to establishing program correctness receive attention. (II) Elements of top-down programming are sketched out and then examined in detail. An extended critique of another top-down experiment provides example material. (III) Powers of various structured control constructs are compared within a framework of weak and strong program equivalence. Results include a demonstration that Dijkstra's D-programs are strongly equivalent to programs built from functions and one-input/two-output predicates. (IV) After a review of Quine's notion of referential transparency, the author examines elements of good and bad programming practice. In addition, a table of programming proverbs provides guidance to a programmer, and should be especially useful to a novice. (V) Discussions on problem and program specification provide an introduction to a review of proof-of-correctness techniques. Then, noting some practical limitations on proving correctness, the author goes on to examine selected facets of program synthesis.

TN844. Designs for the calibration of small groups of standards in the presence of drift, J. M. Cameron and G. E. Hailes, Nat. Bur. Stand. (U.S.), Tech. Note 844, 35 pages (Aug. 1974) SD Catalog No. C13.46:844, 70 cents.

Key words: calibration; calibration design; experiment design; instrumental drift; measurement process; statistical analysis; trend elimination.

The process of calibrating a small number of "unknown" standards relative to one or two reference standards involved determining differences among the group of objects. Drift, due most often to temperature effects, or a "left-right" polarity effect can bias both the values assigned to the objects and the estimate of the effect of random errors. This note presents schedules of measurements of differences that eliminate the bias from these sources in the assigned value and variances at the same time gives estımates of the magnitude of these extraneous components. The use of these designs in measurement process control is discussed and a computer program in BASIC is presented.

NBSIR 73-214. LEAA police equipment survey of 1972, Volume V: Handguns and handgun ammunition, S. Bergsman, E. Bunten, and P. Klaus, 102 pages (July 1971-Aug. 1973). Order from NTIS as COM 74-11239.

Key words: ammunition; handguns; police; police equipment; standards.

The report outlines the methodology of and summarizes a portion of the data from the LEAA Police Equipment Survey of 1972. One of a series of seven reports resulting from this nationwide mail survey of a stratified random sample of police departments, the present report summarizes the answers of 445 police departments concerning their officers' use of handguns and handgun ammunition: on-duty and offduty use, types and calibers in use, and problems encountered. The data are presented by all responding departments and by seven department types.

NBSIR 73-421. An overview of the factors impacting metrication of the U.S. housing industry, R. G. Hendrickson and D. W. Corrigan, 35 pages (Dec. 1973). Order from NTIS as COM 74 . 11224.

Key words: codes; construction conference; domestic housing, U.S.; foreign metrication; levels of conversion; metrication; problems of metrication.

This report describes the work undertaken by the National Bureau of Standards for the Department of Housing and Urban Development to ascertain and delineate major problems associated with the metrication of the domestic housing industry of the United States. Source material for the study included, principally, the foreign experiences 
of Great Britain and Australia; information obtained from interviews with businesses and associations; depositions provided to the 1970 Construction Conference, held for the purposes of the U.S. Metric Study; and documents, both foreign and domestic, pertaining to aspects of metrication.

The results of the study indicate the critical impact of metrication will be the redefinition or accommodation of the 15,000 codes at the local level, and the coordination of the 127 standard-setting organizations in the United States to define, develop and implement standards consonant with requirements and desired industry goals.

NBSIR 73-422. A study of air traffic data requirements and sources for FAA analyses, W. F. Druckenbrod, J. F. Gilsinn, R. H. F. Jackson, L. S. Joel, and T. K. Ming, 51 pages (May 1974) Order from NTIS as COM 74-11240.

Key words: air traffic analyses; air traffic data; standard reference air traffic data; users of air traffic data.

This report describes activities undertaken to assess the practicability of establishing a single file or a set of files of standard reference air traffic data samples. These files would serve as a common data base for ongoing and anticipated future forecast and analytical in vestigations relevant to the accommodation of air traffic in the $\mathrm{Na}$ tional Airspace System.

The study entailed surveys of past and present air traffic data collection activities, of existing data files, and of all identifiable users of air traffic data within the FAA, as well as FAA contractors whose work requires air traffic data.

The information resulting from these surveys has been evaluated and aggregated to identify data which will satisfy most of the requirements expressed by the data users. Two data sets are specified for terminal area requirements, two sets for enroute requirements, and one set for oceanic requirements. These data sets will satisfy most input requirements for all anticipated analysis efforts. However, depending on the type of study, supplemental information, which is identified in various parts of this report, will be required in some cases.

This column lists all outside publications by the NBS staff, as soon after issuance as practical. For completeness, earlier references not previously reported may be included from time to time.

Abraham, B. M., Ketterson, J. B., Roach, P. R., Pfeiffer, E. R., Demagnetization experiments on some promising new compounds for very low-temperature refrigeration, J. Low Temp. Phys. 14, Nos. 3/4, 387-396 (1974).

Key words: adiabatic magnetization; cerium compounds; cerium magnesium nitrate; low temperature thermometry; magnetic temperature; paramagnetic compounds.

We have performed demagnetization experiments on spherical specimens of silver chloride-bonded, compacted powders of four different compounds. Pure and lanthanum-diluted cerium magnesium nitrate (CMN) was studied along with two new compounds formed from cerium iodide and antipyrine and from cerium thiocyanate and triphenyl phosphine oxide. The magnetic temperatures $\mathrm{T}^{*}$ were determined from measurements of the magnetic susceptibility perpendicular to the axis of the initial magnetizing field. Both the lanthanum-diluted CMN and the triphenyl phosphine oxide compounds yielded significantly lower values of $\mathrm{T}^{*}$ than that obtained with CMN. The problem of thermal equilibrium within the demagnetized sample is considered.

Achenbach, P. R., Coble, J. B., Site analysis for the application of total energy systems to housing developments, Proc. 7 th Intersociety Energy Conversion Engineering Conf., San Diego, Calif., Sept. 25-29, 1972, pp. 1-31 (Sept. 1972).

Key words: air conditioning; air pollution; central utility systems; electric power generation; energy conservation; energy costs; heat recovery, power systems; total energy systems; utilities for housing.
In early 1970 the Department of Housing and Urban Development approved a program to design and construct about 2800 dwelling units on eleven sites in the United States with the objective of encouraging the industrialization of the home-building process. It was also decided that as a part of this program, Operation BREAKTHROUGH, a full-scale field study would be made to determine whether or not total energy systems could provide economical and reliable energy services to apartment complexes and maintain a high level of environmental quality.

The characteristics of the eleven sites that were important in determining their suitability for a total energy system were studied by the National Bureau of Standards as a basis for selection. Fourteen parameters related to site planning, climate, building design, load factors, cost for fuel, equipment and maintenance, and the interest of the builders and developers were investigated in the feasibility study. The study resulted in the choice of Jersey City, N.J. as the preferred location for the pilot installation of a total energy system and the identification of three other sites of lower priority.

Achenbach, P. R., Energy conservation in buildings: Its foundation, cost, and acceptance, Proc. Conf. Energy Conservation: Implications for Building Design and Operation, Bloomington, Minn., May 23, 1973, pp. 44-73 (1973).

Key words: building design; building performance; building research; building systems; energy conservation; energy use; mechanical systems.

Changes in building practice could save substantial amounts of energy and ease the impending shortages of fuel in the United States. However, changes that are technically sound must also be economically sound, and they must be implemented on a broad scale by the building industry if they are to have a significant impact on fuel usage. The National Bureau of Standards is carrying out significant analytical, laboratory and field investigations of promising technology in energy-saving potential of these building practices. The more extensive field studies are collaborative efforts with other Federal agencies. Concurrently, existing technical information on energy conservation is being collected and prepared as brochures for convenient use by the building design profession and for use in building standards and specifications of various Federal agencies. The program of the National Bureau of Standards on energy conservation in building is summarized and research opportunities in the field are identified for both new and existing buildings.

Allan, D. W., Barnes, J. A., Some statistical properties of LF and VLF propagation, (Proc. AGARD/EPC 13th Symp., Ankara, Turkey, Oct. 9-12, 1967), Chapter 15 in AGARD Conference Proceedings No. 33, Phase and Frequency Instabilities in Electromagnetic Wave Propagation, K. Davies, Ed., pp. 219-230 (Technivision Services, Slough, England, July 1970).

Key words: flicker noise; phase fluctuations of VLF and LF transmissions; statistical analysis.

A statistical analysis has been conducted on the day-time phase fluctuations of the standard frequency and time Radio Stations WWVB $(60 \mathrm{kHz})$ and WWVL $(20 \mathrm{kHz})$ as received at Palo Alto, Calif., and of WWVB as received at the National Research Council, Ottawa, Canada. The analysis technique allows a meaningful determination of the low frequency spectral density, of the variance of the phase and frequency fluctuations, and of some cross-correlations. The analysis techniques used are appropriate for commonly encountered nonstationary as well as stationary noise processes.

The results of the analysis yielded a spectral density of the time fluctuations proportional to the reciprocal spectral frequency $\left(\mathbf{S}_{t}(\omega)=\right.$ $\mathrm{h} /|\omega|$, flicker noise) for the propagation noise on both WWVL and WWVB. The value of $\mathrm{h}$ was equal to $7.9 \times 10^{-14} \mathrm{~s}^{2}$ for WWVL and 2.2 $\times 10^{-14} \mathrm{~s}^{2}$ for WWVB for the Palo Alto path, and $\mathrm{h}$ was $4.4 \times 10^{-14} \mathrm{~s}^{2}$ for WWVB over the Ottawa path. For flicker noise phase modulation a good model of the standard deviation of the fractional frequency 
fluctuations is: $\sigma=\mathrm{k}|\tau|^{-1}$, where $\tau$ is the sample time in days. The values of $\mathrm{k}$ were $2.4 \times 10^{-11}$ days for WWVL and $1.2 \times 10^{-11}$ days for WWVB over the Palo Alto path and $1.8 \times 10^{-11}$ days for WWVB over the Ottawa path.

A cross-correlation coefficient of -0.6 was found between WWVL and WWVB for the Palo Alto path. A linear combination of the two transmissions improved the flicker noise level by a factor of 11.5 over WWVL and by a factor of 2.7 over WWVB, allowing a precision of frequency measurement of $1 \times 10^{-12}$ for a nine day average any time of the year and of $1 \times 10^{-12}$ for a five day average over the summer months.

Allan, D. W., Blair, B. E., Davis, D. D., Machlan, H. E., Precision and accuracy of remote synchronization via portable clocks, Loran C, and network television broadcasts, Proc. 25th Annual Symp. on Frequency Control, Atlantic City, N.J., Apr. 26-28, 1971, pp. 195-208 (Electronic Industries Assn., Washington, D.C., 1971).

Key words: cesium beam standards; frequency standards; Loran C; portable clocks; time synchronization; TV timing.

Three precise timing centers in the U.S. have made remote time comparisons for over a year using three different synchronization methods. The timing centers were the U.S. Naval Observatory (USNO), Washington, D.C.; Newark Air Force Station (NAFS), Newark, Ohio; and the National Bureau of Standards (NBS), Boulder, Colo. The synchronization methods were cesium beam portable clocks; Loran C transmissions from North Carolina and Indiana; and ABC, CBS, and NBC live network TV broadcasts common to the three timing centers. Cesium beam portable clocks, having capabilities of accurately and precisely synchronizing remote clocks to within $0.1 \mu \mathrm{s}$, formed the basis of comparison. This method is one of the most accurate now available. The Loran $\mathrm{C}$ data were taken over a $3150 \mathrm{~km}$ (1958 mi) ground wave path, which is believed the longest such path studied with the precision and accuracy of our results. The long term precision between the three remote time centers was better than $2 \mu$ s via Loran C; the accuracy of these data is limited by $10 \mu \mathrm{s}$ ambiguity in identifying the proper cycle of the $100 \mathrm{kHz}$ pulse train. The precision of the TV broadcasts in synchronizing remote clocks was $30 \mathrm{~ns} \mathrm{~T}^{12} \mathrm{~d}^{-12}$, where $\mathrm{T}$ is in days. Factors such as occasional rerouting of TV network signals limited the accuracy. Relative frequency stabilities between ensembles of cesium beam standards at the three time centers were a few parts in $10^{14}$ for sample times of about three months.

Allpress, J. G., Iijima, S., Roth, R. S., Stephenson, N. C., Structural studies by electron microscopy: High-résolution observations on $\boldsymbol{\beta}-\mathrm{ZrO}_{2} \cdot 12 \mathrm{Nb}_{2} \mathbf{O}_{5}$, J. Solid State Chem. 7, 89-93 (1973).

Key words: $\beta-\mathrm{ZrO}_{2} \cdot 12 \mathrm{Nb}_{2} \mathrm{O}_{5}$; electron microscopy; high resolution; structural studies.

Reliable idealized structures for the $\beta$ and $\gamma$ forms of $\mathrm{ZrO}_{2}$. $12 \mathrm{Nb}_{2} \mathrm{O}_{5}$ have been deduced following the observation of lattice images, recorded at a resolution of about $0.3 \mathrm{~nm}$, from crystals oriented with their short $b$ axes parallel to the incident electron beam. The structure of the $\beta$ form is confirmed by preliminary results from single crystal $x$-ray studies. The present observations are compared with previous work on these phases.

Ambrose, J. R., Kruger, J., Tribo-ellipsometric study of the repassivation kinetics of a Ti 8Al-1Mo-1V alloy, J. Electrnchem. Soc. 121, No. 5, 599-604 (May 1974).

Key words: repassivation kinetics; stress corrosion cracking; titanium alloy; tribo-ellipsometry.

The tribo-ellipsometric technique allows one to distinguish between film growth and other reactions that occur after removal of a film from a metal surface in a given environment. This technique was used to study the relationship between repassivation kinetics and stress corrosion cracking (SCC) susceptibility for Ti 8Al-1Mo-1V al- loy. In these studies the effect of the rate of film growth on the amount of metal dissolution which occurs during the repassivation process was investigated by comparing the repassivation transient behavior in a $1.0 \mathrm{~N} \mathrm{NaCl}$ solution, where cracks have been found to propagate, to that in a $1.0 \mathrm{~N} \mathrm{NaNO}$ solution where $\mathrm{SCC}$ susceptibility has never been detected. Film growth kinetics in both solutions were consistent with a Fleischmann-Thirsk mechanism of oxide patch nucleation and two-dimensional growth, although the film growth rate was significantly slower in the $1.0 \mathrm{~N} \mathrm{NaCl}$ solution. Low film growth rate led to an increase in metal dissolution in a solution where crack propagation velocities have been measured, but at an apparent rate slower than necessary to propagate such cracks by metal dissolution alone.

Andrews, J. R., Random sampling oscilloscope for the observation of mercury switch closure transition times, IEEE Trans. Instrum. Meas. IM-22, No. 4, 375-381 (Dec. 1973).

Key words: mercury switch; oscilloscope; picosecond; pulse; random sampling; risetime; sampling; transition time.

With the advent of new miniaturized mercury $(\mathrm{Hg})$ switches with reputed transition times of the order of $10 \mathrm{ps}$, interest has been rekindled in their use in high-speed pulse measurements. Since there is no pretrigger signal available from a $\mathrm{Hg}$ switch, normal sequential sampling techniques are not useable to measure the fast $\mathrm{Hg}$ switch transition time. For this reason, a new random sampling time base unit was designed to perform these measurements at the low repetition rate of $\mathrm{Hg}$ switches. The time base may be used with commercial sampling oscilloscope systems through suitable interconnection terminals or possible interface equipment. It features three selectable time windows of $1 \mu \mathrm{s}, 100 \mathrm{~ns}$, and $10 \mathrm{~ns}$. Using its time magnifier, the fastest sweep rate is $10 \mathrm{ps} / \mathrm{cm}$. A variable trigger lead time control is provided. The trigger sensitivity is $5 \mathrm{mV}$.

Arnett, R. W., Voth, R. O., A computer program for the calculation of thermal stratification and self-pressurization in a liquid hydrogen tank, NASA CR-2026, 131 pages (National Aeronautics and Space Administration, Washington, D.C., May 1972).

Key words: computer program; cryogenic; liquid hydrogen; mathematical model; self pressurization; thermal stratification.

This report describes an analysis and computer program used to calculate the thermal stratification and the associated self pressurization of a closed liquid hydrogen tank. A sample calculation is provided as well as a description and listing of the program. Fortran-IV language is used and runs have been made on IBM 360/65 and CDC 3600 computers. Comparisons are made between the program calculations and test results from both ground and orbital coast tests of a Centaur space vehicle.

Arora, V. K., Peterson, R. L., Theory of magnetophonon structure in the longitudinal magnetothermal emf, Phys. Rev. B 9, No. 10, 4323-4328 (May 15, 1974).

Key words: magnetophonon effect; Seebeck effect; semiconductor; transport.

The magnetophonon effect, as manifested in the longitudinal magnetothermal emf (Seebeck coefficient $Q_{z z}$ ), is examined analytically and numerically in the limit of no Landau-level broadening, for combined optic and acoustic-phonon scattering of electrons in nonpolar semiconductors. In addition to off-resonance maxima occurring at magnetic fields somewhat larger than those given by the GurevichFirsov resonance condition $N \omega_{c}=\omega_{0}, N=1,2, \ldots$, where $\omega_{c}$ and $\omega_{0}$ are the cyclotron and optic-phonon frequencies, discontinuities in the derivative of $Q_{z z}$ with respect to magnetic field are found. The slope discontinuities lie precisely at $N \omega_{c}=\omega_{0}$ and at $(2 n+1) \omega_{c}=2 \omega_{0} n=$ $0,1, \ldots$, yielding additional structure characterized by $\partial\left|Q_{z z}\right| / \partial B_{-}>$ $\partial\left|Q_{z z}\right| / \partial B_{+}$at all temperatures and degrees of elastic scattering. 
Ball, J. J., Device for stabilizing electrodeless discharge lamps, Rev. Sci. Instrum. 44, No. 8, 1141 (Aug. 1973).

Key words: atomic spectroscopy; electrodeless lamps.

Increased stability for electrodeless discharge lamps used in atomic spectroscopy is attained by mounting a heater coil below the lamp. Heating by convection maintains the lamp at a constant temperature resulting in stable output within 2 percent.

Barnes, J. A., Winkler, G. M. R., The standards of time and frequency in the U.S.A., Proc. 26th Annual Frequency Control Symp., Atlantic City, N. J., June 6-8, 1972, pp. 269-278 (Electronic Industries Assn., Washington, D.C., 1972).

Key words: astronomical time; atomic time; frequency; International Atomic Time; management; NBS; standard time; time; USNO.

The National Bureau of Standards (NBS) and the U.S. Naval Observatory (USNO) are the two organizations chiefly involved in distributing accurate and precise time and frequency information within the U.S.A. The NBS is responsible for the "custody, maintenance, and development of the national standards" of frequency and time (interval) as well as their dissemination to the general public. The mission of the USNO includes the "provision of accurate time" as an integral part of its work concerned with the publication of ephemerides in support of navigation and in the establishment of a fundamental reference system in space.

Both agencies provide the U.S. contribution to the Bureau International de l'Heure (BIH) [International Time Bureau], which has the responsibility of publishing definitive values of Universal Time (UT), International Atomic Time (LAT), and Coordinated Universal Time (UTC).

Bay, Z., The constancy of the velocity of light and prospects for a unified standardization of time, frequency and length, (Proc. 4th Int. Conf. on Atomic Masses and Fundamental Constants, Teddington, England, Sept. 6-10, 1971), Chapter in Atomic Masses and Fundamental Constants, J. H. Sanders and A. H. Wapstra, Eds. 4, 323-336 (Plenum Press, London, England, 1972).

Key words: accuracy limits in interferometry; experimental evidences for constancy of speed of light; unified primary standard for time and length.

Light propagation in vacuum is experimentally proven to be dispersionless to within accuracies exceeding by many orders those of measurements in metrology. The independence of $\mathrm{c}$ relative to the motion of the frame connected to the moving earth is established less accurately, but accurate enough for metrology; any departure from constancy would affect length measurements, based on wavelength standards, or based on c, in the same way. It can be expected that in the not too distant future 1) optical frequencies in the infrared and visible spectrum can be measured at least as accurately as length can be measured, and 2) that the speed of light will be known to the accuracy of the present length standard. If 1) and 2) materialize then, on both theoretical and practical grounds, the unified standardization of time interval, frequency and length via an agreed upon value of $c$ will be preferable to a system based on a frequency standard and on a wavelength standard.

Beatty, R. W., A frequently reinvented circuit (abstract), IEEE Trans. Microwave Theory Tech. Letter to Editor MTT-22, No. 5, 58 (May 1974).

Key words: directional couplers; impedance measurement.

Attention is called to published work describing an impedancemeasuring circuit that is frequently reinvented.

Benjamin, I. A., Parker, W. J., Fire spread potential of ABS plastic plumbing, Fire Technol. 8, No. 2, 104-119 (May 1972).
Key words: ABS, building fires; drain pipe; fire spread; pipe chase; smoke; temperature; vent pipe; waste pipe.

Eight chases, each with a different drain, waste, and vent pipe installation, were subjected to the standard ASTM E119 fire exposure for up to 2 hours duration. These tests were designed to examine the possibility of vertical fire spread from one room to another via a chase containing ABS pipes and fittings; and to identify the type of installation least susceptible to fire spread.

The best performance should be obtained when the ABS lateral enters the smoke-tight chase at a downward angle of $45^{\circ}$ and is enclosed in a steel sleeve at the point of penetration of the chase wall.

Benjamin, I. A., The criteria for fire safety in Operation BREAKTHROUGH, Bldg. Stand. 40, No. 6, 32-36 (Nov.-Dec. 1971).

Key words: fire resistance; fire safety; housing performance; life safety.

The presentation gives the philosophical background for some of the criteria which have been used for evaluation of innovative housing in Operation BREAKTHROUGH. Particular attention is given to a modified concept of fire resistance, the introduction of new types of material controls and the concept of life safety system for residential construction.

Benjamin, I. A., The influence of fire-resistant design on survival, Proc. Symp. Designing to Survive Disaster, Illinois Institute of Technology Research Institute, Chicago, Ill., Nov. 6-8, 1973, pp. 263-282 (1973)

Key words: building fires; design; evacuation; fire alarms; fire protection; fire resistance; fire safety; fire spread; fire statistics; fire suppression; high rise buildings; ignition source; life safety; refuge areas; smoke control.

Annual fire losses in the U.S. approximate 12,000 deaths and over $\$ 2$ billion direct property damage. New materials and new methods of construction have produced new potential fire hazards which increase the threat to life, especially in tall, densely-populated buildings. Data are presented showing the most common ignition sources for building fires. Fire safety must be included at the earliest stages of building design, in order to assure that it is systematic and adequate to protect lives. Several methods of dealing with the fire problem are described, including prevention of ignition, containment of fire and smoke within a limited space, automatic and manual methods of fighting fire, and provisions for life safety. Smoke often causes death before flames and heat reach the building occupants and, therefore, engineered smoke control design measures must be a major provision to protect lives. Problems with total evacuation of high rise and institutional buildings are described, and new life safety concepts, such as refuge areas, are suggested as alternatives. As buildings become more complex and hazardous construction materials become more prevalent, it is increasingly important to design ahead for fire prevention so that protection is in the building when it is built, not as an afterthought.

Blackburn, D. L., Schafft, H. A., Swartzendruber, L. J., Nondestructive photovoltaic technique for the measurement of resistivity gradients in circular semiconductor wafers, J. Electrochem. Soc. 119, No. 12, 1773-1778 (Dec. 1972).

Key words: germanium; inhomogeneities; measurement methods; photovoltaic efffect; resistivity; semiconductors; silicon.

The bulk photovoltaic effect is applied to the measurement of radial resistivity gradients in circular semiconductor wafers. This nondestructive technique permits a continuous measurement of the resistivity variation to be made by contacting only the rim of the wafer. An expression relating the radial resistivity gradient to the photovoltage measured at the wafer rim is derived and used to calculate the re- 
sistivity profile. Photovoltaic resistivity profiles, which were made on silicon and germanium wafers with resistivities ranging from $1 \Omega \cdot \mathrm{cm}$ to $5000 \Omega \cdot \mathrm{cm}$, generally agree well with two- and four-probe resistivity profiles in the central portion of the wafer. Lack of agreement observed at positions in the outer half of the wafer is discussed in terms of basic material parameters, electrical contact quality, and measurement precision of the four-probe method.

Blevin, W. R., Geist, J., Influence of black coatings on pyroelectric detectors, Appl. Opt. 13, No. 5, 1171-1178 (May 1974).

Key words: black coatings; detectors; gold-black; pyroelectric; radiometry.

The extent to which the thermal capacitance and resistance of a black coating on a pyroelectric detector offset the gain in optical absorptance is investigated. A black paint is shown to be of little value, but a coating of gold-black may increase the detector responsivity for modulation frequencies up to at least several kilohertz. When a coated pyroelectric detector is calibrated electrically, a correction is necessary for the thermal impedance of the black. For gold-blacks of superficial density $2 \mathrm{~g} \mathrm{~m}^{-2}$, this correction is shown to be less than 2 percent for frequencies within the $0-100-\mathrm{Hz}$ range.

Block, S., Piermarini, G. J., The melting curve of sulfur to 300 C and 12 kbar, High Temp.-High Pressures 5, 567-573 (1973).

Key words: diamond-anvil cell; high pressure; melting curve; polymorphism; sulfur.

The melting curve of sulfur has been studied to $300{ }^{\circ} \mathrm{C}$ and $12 \mathrm{kbar}$ using a diamond-anvil high-pressure cell and an optical system which utilizes the ruby-fluorescence $R_{1}$ line shift for measuring the pressure. Two triple points were determined in this temperature range: (i)L-IV-VI at $(235 \pm 5)^{\circ} \mathrm{C}$ and $(8 \cdot 5 \pm 1) \mathrm{kbar}$, and (ii)L-VI-VIII at $(290$ $\pm 5)^{\circ} \mathrm{C}$ and $(12 \pm 5)$ kbar. Because of the nonequilibrium behavior of sulfur the melting curve could not be characterized with any degree of certainty above $235^{\circ} \mathrm{C}$.

Brown, D. W., Lowry, R. E., Wall, L. A., Radiation-induced polymerization at high pressure of 2,3,3,3tetrafluoropropene in bulk and with tetrafluoroethylene, J. Polymer Sci. 9, Part A-1, 1999-2007 (1971).

Key words: polymerizing material; propene; radiation-induced polymerization; tetrafluoroethylene; tetrafluoropropene.

The radiation-induced polymerization of 2,3,3,3-tetrafluoropropene was studied as a function of temperature $\left(22-100{ }^{\circ} \mathrm{C}\right)$ and pressure (autogenous to $10^{4} \mathrm{~atm}$ ). Rates have varied 100 -fold for the same reaction conditions probably because of trace impurities. The most rapidly polymerizing material has a rate of 4.5 percent $/ \mathrm{hr}$ at $6000 \mathrm{~atm}$, $22{ }^{\circ} \mathrm{C}$, and $1500 \mathrm{rad} / \mathrm{hr}$. The activation enthalpy and volume are 4 $\mathrm{kcal} / \mathrm{mole}$ and $-13 \mathrm{cc} /$ mole, respectively. Rates are proportional to the square root of the radiation intensity. Degrees of polymerization varied between $2 \times 10^{3}$ and $2 \times 10^{6}$. In copolymerization with tetrafluoroethylene the reactivity ratios at $22^{\circ} \mathrm{C}$ and $5000 \mathrm{~atm}$ are 0.37 (the ratio for addition to the tetrafluoroethylene-ended radical) and 5.4 (the ratio for addition to the tetrafluoropropene-ended radical). Comparison of ratios for the copolymerization of other fluorinecontaining monomers with tetrafluoroethylene shows that they generally disfavor incorporation of the latter.

Buehler, M. G., Thermally stimulated measurements: The characterization of defects in silicon $p-n$ junctions, Semiconductor Silicon, pp. 549-560 (1973).

Key words: defect centers; $p$ - $n$ junction; semiconductor characterization; silicon; thermally stimulated measurements.

Thermally stimulated capacitance and current measurements utilize the ability of defects in the vicinity of a $p-n$ junction to trap holes or electrons and to emit them after receiving sufficient thermal ener- gy. Values for defect densities, energy levels, and emission rates can be derived from these measurements where the limit of detectability can be as low as $10^{10}$ defects $/ \mathrm{cm}^{3}$. From these values the atomic nature of the defects can be identified.

Cali, J. P., An idea whose time has come (guest editorial), Clin. Chem. 19, 291-293 (1973).

Key words: accuracy; clinical chemistry; health.

An editorial stressing the importance of achieving accuracy in the methods used in clinical chemistry. Meaningful measurement systems have five requirements: (1) agreement on a rational system of base units; (2) well-characterized materials (e.g., NBS-SRM's) that together with (3) referee methods of proven accuracy are used to realize these units and their derivatives; (4) field methods used in practical application to be tested for accuracy by (2) and (3); and, (5) a quality control assurance program to insure the long-term integrity of the measurement system.

Actions initiated and completed within the past 3 years are stated showing that the achievement of accuracy in clinical chemistry is underway. A plea for an acceleration of this process is made.

Cali, J. P., A systematic approach to accuracy in clinical chemistry, Med. Instrum. 8, No. 1, 17-21 (1974).

Key words: accuracy; clinical chemistry; meaningful measurement.

When measurements made in clinical chemistry laboratories are "meaningful," the values obtained are accurate, precise, and specific. The latter two characteristics, related to reproducibility and singularity respectively, represent no great problem in clinical chemistry measurements. Accuracy, however, which is related to the "true" value, remains a somewhat elusive goal. Unless a measurement system is based on accuracy, comparison of results obtained over time and distance in different laboratories may lead to doubtful or misleading conclusions. A meaningful measurement system consists of five parts: (1) a rational, self-consistent, agreed-on system of units of measurement; (2) well characterized materials used in conjunction with; (3) referee methods of known accuracy to realize in practice the base units and their derivative; (4) field or applied methods of measurement, assessed for accuracy via parts 2 and 3 ; and (5) a process whereby the long-term integrity of the measurement system is assured.

\section{Cali, J. P., Problems of standardization in clinical chemistry Bull.Wld. Hlth. Org. 48, 721-726 (1973).}

Key words: accuracy; analysis; clinical chemistry; measure ment; precision; referee methods; specificity; standarc reference materials.

If analytical results in clinical chemistry are to be made meaningful, i.e., accurate, precise, and specific, a systematic approach to their attainment is necessary. Furthermore, because this system is so complex in scope and the need for it is so widespread, it will require international coordination. Agreement on the units of measurement, the production and certification of standard reference materials, and the development of reference methods of demonstrated accuracy will require the support of all segments of clinical chemistry.

Carpenter, B. S., LaFleur, P. D., Nitrogen determination in biological materials by the nuclear track technique, Anal. Chem. 46, No. 8, 1112-1113 (July 1974).

Key words: bovine liver, cellulose nitrate; image analyzing system; microscope; neutron activation analysis; nitrogen; orchard leaves; proton tracks; Standard Reference Materials.

A method has been developed for the determination of nitrogen in biological matrices using the nuclear track technique (NTT). Protons from the nuclear reaction ${ }^{14} \mathrm{~N}(\mathrm{n}, \mathrm{p}){ }^{14} \mathrm{C}$, which is produced by thermal neutrons, leave radiation damaged trails (tracks) which are made visi- 
ble to optical microscopy by chemical etching. The NTT method has been used for the analysis of leaves and liver with excellent agreement with values obtained using the Kjeldahl technique.

Carpenter, B. S., Lithium determination by the nuclear track technique, (Proc. Int. Conf. Modern Trends in Activation Analysis, Saclay, France, Oct. 1-6, 1972), J. Radionanal. Chem. 19,233234. (1974).

Key words: alpha tracks; biological material; image analyzing system; lithium; microscope; nuclear track technique; standard reference material.

The Nuclear Track Technique was used to determine lithium in Biological Standard Reference Material 1571 (Orchard Leaves). Alpha tracks produced in cellulose acetate (CA) from the nuclear reaction ${ }^{6} \mathrm{Li}(\mathrm{n}, \alpha)^{3} \mathrm{H}$ with thermal neutrons were counted to determine the concentration of lithium present. The method of standard additions was used and, with least squares analysis of the data, the lithium concentration was found to be $13.72 \pm 1.50 \mathrm{ppm}$.

Cassel, J. M., Aggregation phenomena of collagen, Chapter 2 in Biophysical Properties of the Skin, H. R. Elden, Ed., pp. 63-100 (John Wiley \& Sons, Inc., New York, N.Y., 1971).

Key words: aggregation; collagen; fibrils; hydrophobic bonding; native-type fibril formation; phase transition; precipitation kinetics.

Various aggregation phenomena exhibitied by dissolved collagen are reviewed. Main consideration is given to native-type fibril formation. The kinetics and thermodynamics of this precipitation process are examined. Subtopics included are phase diagram determinations, hydrophobic bonding aspects, time-dependent changes in the reversibility of native-type fibril precipitation, and the role of polyanions. The review is concluded with discussion of collagen fibril formation in vivo.

Cassidy, E. C., Anderson, W. E., Booker, S. R., Recent refinements and developments in Kerr system electrical measurement techniques, IEEE Trans. Instrum. Meas. IM-21, No. 4, 504-510 (Nov. 1972).

Key words: electric fields; electrical measurements; electro-optics; high-speed photography; high-speed techniques; high-voltage measurements; Kerr effect; laser application; optical techniques; pulse measurements.

Kerr system electrical measurement techniques are improved by progress in two important areas: 1) in the development of methods for visualizing and measuring pulsed (microsecond) electric fields and iigh voltages from time-varying electrooptical fringe patterns recorded using high-speed photographic techniques, and 2) in the development of convenient experimental methods for evaluating and correcting path-dependent errors in Kerr system response. Results demonstrate use of fringe-pattern measurements in achieving accurate pulse voltage measurements and in correction of errors resulting from sizeable end-field variations in existing $300-\mathrm{kV}$ Kerr cells.

Cezairliyan, A., A high-speed (subsecond) system for accurate thermophysical measurements at high temperatures, (Paper 73-743, Proc. AIAA 8th Thermophysics Conf., Palm Springs, Calif., July 16-18, 1973), Chapter in Thermophysics and Spacecraft Thermal Control 35, 205-228 (MIT Press, Cambridge, Mass., 1974).

Key words: electrical resistivity; emittance; heat capacity; highspeed measurements; high temperatures; thermophysics.

A system is described for the high-speed (subsecond) accurate measurement of selected thermophysical and related properties of electrically conducting substances in the temperature range $1500 \mathrm{~K}$ to the melting point of the specimen. The method is based on rapid resistive self-heating of the specimen from room temperature to any desired high temperature in less than $1 \mathrm{sec}$ by the passage of electri- cal currents through it and on measuring and recording the experimental quantities every $0.4 \mathrm{msec}$ with a full-scale signal resolution of one part in 8000 . The system has been used to measure heat capacity, electrical resistivity, hemispherical total emittance, normal spectral emittance, and the melting point of niobium, molybdenum, tantalum, tungsten, some refractory alloys, and graphite. The results of preliminary experiments have shown the potential application of the system to measurements of temperatures and energies of solid-solid phase transformations, heat of fusion, and thermal expansion at high temperatures.

Christ, B. W., Picklesimer, M. L., The relationship between Luder's strain, testing system compliance and other phenomenological variables affecting serrated yielding of recrystallized iron, Acta Met. 22, 435-447 (Apr. 1974).

Key words: compliance; Luder's strain; recrystallized iron; serrated yielding; tensile test.

Constant cross-head speed uniaxial tensile tests were conducted on recrystallized iron wires $(0.0016 \mathrm{~m}$ diameter $)$ which exhibited serrated yielding as a single Luder's band front advanced intermittently from one grip to the other. The ranges of temperature and cross-head speed were, respectively, 383 and $508 \mathrm{~K}$ and $8.3 \times 10^{-7}-8.3 \times 10^{-6}$ $\mathrm{m} / \mathrm{s}$. Average load drop amplitude, $\overline{\Delta L}$, was about 25 percent of the peak stress.

The effect of testing system compliance, $C$, on the number of equal load drops, $n$, during serrated yielding was determined. It was found that the number of load drops decreased as compliance increased. The following relationships for average Luder's band front advance during a single load drop was established,

$$
\bar{a}_{i}=l_{0} / n
$$

where $l_{0}=$ gage length. Furthermore, it was demonstrated that average Luder's strain during the $i$ th load drop, $\bar{\epsilon}_{i}$, is given by

$$
\bar{\epsilon}_{i}=C_{i} \Delta L_{i} / \bar{a}_{i}=n C_{i} \Delta L_{i} / l_{0} .
$$

It was concluded that analysis of the $i$ th load drop is a valuable new method for studying Luder's strain during serrated yielding.

Clark, A. F., Hust, J. G., A review of the compatibility of structural materials with oxygen, AIAA J. 12, No. 4, 441-454 (Apr. 1974).

Key words: compatibility; materials; metals; oxygen; safety; survey.

The compatibility of structural materials, particularly metals, with gaseous and liquid oxygen is reviewed. Various methods of testing for oxygen compatibility are described. The literature is reviewed with respect to accidents, experimental measurements of ignition and combustion, the effect of high pressure, theory, and properties data. The relative compatibility of various materials is discussed and a selection procedure recommended. Needed future research is also outlined.

Clough, R. B., Simmons, J. A., A theory of multiaxial plasticity based on integral dislocation dynamics, Acta Met. 22, 513521 (May 1974).

Key words: dislocations; plasticity; thermal activation.

A macroscopic theory of isotropic plastic flow under multiaxial stress states is developed from considerations of thermally activated dislocation motion on discrete randomly-oriented slip planes. The resulting equations are in agreement with classical plasticity theory. Yielding is volume-preserving, pressure-independent, and the principal stress and principal strain axes coincide. The flow surface is constructed on the basis of constant power dissipation of plastic flow, and has a variable shape and orthogonal strain vector. For most materials, the predicted flow surface resembles the Tresca yield surface at low temperatures and approaches the von Mises yield surface as its high temperature limit. Other applications are discussed. 
Coble, J. B., Achenbach, P. R., Description of equipment and instrumentation for a field study of a total energy system in an apartment development, Proc. 7th Intersociety Energy Conversion Engineering Conf., San Diego, Calif., Sept. 25-29, 1972, pp. 1-27 (Sept. 1972).

Key words: data acquisition system; electrical power system; energy conservation; fuel utilization; thermal efficiency; thermal energy system; total energy system; utility system performance; waste heat recovery.

The Department of Housing and Urban Development selected the BREAKTHROUGH site at Jersey City, N.J. as the location for an installation and field study of a total energy system. This development covers six acres, and is comprised of four buildings containing 488 dwelling units, a small building for commercial use, two small schools, a swimming pool, and the total energy plant. The field study of this installation is being carried out by the National Bureau of Standards to produce much-needed authoritative information on engineering performance, maintenance requirements, and load-andcost data for total energy systems.

The central plant and the individual buildings are being extensively instrumented to provide digital data on fuel utilization, the generation of electrical and thermal energy, the excess heat rejected, and the utilization of electrical and thermal energy by all major segments of the load. A separate analog data system is being employed to obtain recordings of transient conditions of voltage, frequency, current, power factor, and load division during sudden load changes and to record interruptions of service due to overload or malfunction of equipment. The environmental impact of the total energy plant with respect to noise, vibration, air pollution, and aesthetics is also being evaluated.

Cook, R. K., Foreword and introduction for the Symposium on Atmospheric Acoustics and Noise Propagation, $J$. Acoust. Soc. Am. 55, No. 5, 926 (May 1974).

Key words: acoustics; aircraft noise; atmospheric acoustics; infrasound; noise propagation; sound propagation.

Foreword and introduction for the Symposium on Atmospheric Acoustics and Noise Propagation.

Copley, J. R. D., Rowe, J. M., Density fluctuations in liquid rubidium. I. Neutron-scattering measurements, Phys. Rev. A 9, No. 4, 1656-1666 (Apr. 1974).

Key words: coherent scattering function; density fluctuations; liquid rubidium; molecular dynamics; neutron scattering and potential.

We report neutron-scattering measurements of the coherent scattering function $S(Q, \omega)$ of liquid rubidium at $315 \mathrm{~K}$, in the range of wave vectors $1.25 \leqslant Q \leqslant 5.5 \AA^{-1}$. In this range there is no evidence of peaks at finite $\omega$ in $S(Q, \omega)$ plotted at constant $Q$. On the other hand the Fourier transform $F(Q, t)$ exhibits structure, notably for $Q=2.0$ $\AA^{-1}$, which indicates at least two characteristic (wavelength-dependent) relaxation times in the liquid. For wave vectors $>3.0 \AA^{-1}$, $F(Q, t)$ may be characterized by a single relaxation time. These results, in conjunction with our results for $Q<1.0 \AA^{-1}$, offer the possibility of detailed comparisons with models of the liquid state and with molecular-dynamics calculations.

Cox, J. E., Hein, R. A., Waterstrat, R. M., Superconducting properties of Al5 phase V-Pt alloys, Proc. 12th Int. Conf. on Low Temperature Physics, Kyoto, Japan, Sept. 4-10, 1970, pp. 333-334 (Mar. 1971).

Key words: Al5 compounds; atomic ordering; critical magnetic field; superconducting; superconductivity; transition temperatures.

Superconducting transition temperatures, $T_{0}$, and initial slopes of the critical magnetic field curves are reported for $\mathrm{V}$-Pt alloys of the
Al5 crystal structure. Increased atomic ordering produces an increase in $T_{0}$, contrary to our previous results.

Cuthill, J. R., McAlister, A. J., Erickson, N. E., Watson, R. E., X-ray photoemission studies of rare earth hard magnets, (Proc. 19th AIP Conf. on Magnetism and Magnetic Materials, Boston, Mass., Nov. 13-16, 1973), Chapter in Magnetism and Magnetic Materials, C. D. Graham, Jr., and J. J. Rhyne, Eds., pp. 1039-1043 (American Institute of Physics, New York, N.Y., 1974).

Key words: electronic structure; ESCA; hard magnets; magnetic materials; photoelectron spectroscopy; rare-earth magnets; $\mathrm{x}$ ray photoelectron.

In the present investigation we attempt to probe the electronic properties of the $\mathrm{RC}_{0}$ compounds by x-ray photoelectron spectroscopy studies of $\mathrm{SmCo}_{5}$ and $\mathrm{PrCo}_{5}$ and endeavor to relate the results to the properties of the pure metals and to the picture developed to describe the magnetism of the compounds. The results indicate a valencè band structure which is similar to that of Co metal; there is the suggestion that if there is charge flow it is off the rare-earth sites; there appears to be significant change in the $4 \mathrm{f}$ spectra from that of the pure rare-earth metals; and there is a suggestion of $\mathrm{f}$ - $\mathrm{d}$ hybridization.

Davies, J. B., A least-squares boundary residual method for the numerical solution of scattering problems, IEEE Trans. Microwave Theory Tech. MTT-2 1, No. 2, 99-104 (Feb. 1973).

Key words: electromagnetic scattering; least-squares; numerical solution; point-matching.

An explicit least-squares criterion is put forward as an alternative to the point-matching method of numerically solving scattering problems. While being an established method of functional approximation, it has been largely ignored in numerical approaches to electromagnetic scattering.

In contrast to point matching, the least-squares approach has a rigorous proof of convergence. An electric/magnetic weighting factor is found useful in optimizing convergence. Finally, it allows use of perhaps the fastest and most compact matrix inversion algorithm.

Deslattes, R. D., Henins, A., X-ray to visible wavelength ratios, Phys. Rev. Lett. 3 1, No. 16, 972-975 (Oct. 15, 1973).

Key words: conversion factor; interferometer; lattice repeat distance; $\mathbf{x}$-ray; wavelength.

The lattice repeat distance of a nearly perfect single crystal of silicon has been measured in terms of the visible wavelength of a stabilized $\mathrm{He}-\mathrm{Ne}$ laser. This crystal subsequently has been used to diffract reference $\mathrm{x}$-ray lines $\left(\mathrm{Cu} K \alpha_{1}\right.$, Mo $\left.K \alpha_{1}\right)$ thereby establishing their wavelength relative to visible standards. In terms of the $\mathrm{x}$-ray scale in which $\lambda\left(\mathrm{Cu} K \alpha_{1}\right)=1.537400 \mathrm{kxu}$, the conversion factor is $\Lambda_{C u}=1.002$

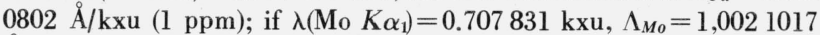
$\AA / \mathrm{kxu}(0.6 \mathrm{ppm})$.

Deslattes, R. D., Sauder, W. C., Intercomparison of micrometer, nanometer and picometer wavelengths, (Proc. 4th Int. Conf. on Atomic Masses and Fundamental Constants, Teddington, England, Sept. 6-10, 1971), Chapter in Atomic Masses and Fundamental Constants, J. H. Sanders and A. H. Wapstra, Eds. 4, 337-347 (Plenum Press, London, England, 1972).

Key words: Avogadro's number; Compton wavelength; gammaray wavelength; lattice parameters; $x$-ray conversion factor; $x$ ray wavelengths.

Reckoning of a common baseline by x-ray and optical interferometry impinges on several fundamental measurements. Our program involves successive wavelength-lattice parameter-lattice parameter-wavelength transfers. Aside from unification of the visible, and x-ray, and $\gamma$-ray wavelength scales, we aim at Avogadro's constant and the electron's Compton wavelength. This report outlines the program, gives current progress, and mentions residual problems. 
Requirements for high resolution linear and angular measuring engines have been met by extensions of available technology. Similarly, density measurements as refined from classical bouyant weighings by Bowman and Schoonover appear adequate.

DeVoe, J. R., Shideler, R. W., Ruegg, F. C., Aronson, J. P., Shoenfeld, P. S., Computer utility for the analytical laboratory, Anal. Chem. 46, No. 4, 509-520 (Apr. 1974).

Key words: computer control; laboratory automation; teleprocessor.

The use of a parallel digital data bus as part of an elaborate teleprocessor system enables the analytical chemist to utilize computer control of his instrument in a manner which is simpler than has been previously described. The use of pushbuttons and thumbwheels with data display, plot, or print in the laboratory, coupled with interactive control of the experiment control program, provides a capability in computer control of instrumentation that approaches the concept of a computer utility. The teleprocessor and software used in a multiprogram environment are described.

Dick, C. E., Lucas, A. C., Motz, J. W., Placious, R. C., Sparrow, J. H., Large-angle $K \mathbf{x}$-ray production by electrons, J. Appl. Phys. 44, No. 2, 815-826 (Feb. 1973).

Key words: aluminum; beryllium; carbon; copper; electron excitation; gold; $K$ x-ray beams; purities; silver; titanium; yields.

Experimental values are given for the yields and spectral energy purities of $K \mathrm{x}$-ray beams emitted at 120 and $180^{\circ}$ from various targets when bombarded by 0.01 - to $3.0-\mathrm{MeV}$ electron beams. Yields and purities are determined for beryllium, carbon, aluminum, titanium, copper, silver, and gold targets as a function of the target thickness and target inclination angle.

Dickens, B., Brown, W. E., Kruger, G. J., Stewart, J. M., Ca $\mathbf{a}_{4}(\mathbf{P O})_{4} \mathbf{O}$, tetracalcium diphosphate monoxide. Crystal structure and relationships to $\mathrm{Ca}_{5}\left(\mathrm{PO}_{4}\right)_{3} \mathrm{OH}$ and $\mathrm{K}_{3} \mathrm{Na}\left(\mathrm{SO}_{4}\right)_{2}$, Acta Crystallog. B29, Part 10, 2046-2056 (Oct. 1973).

Key words: crystal structure; hydroxyapatite; single crystal x-ray diffraction; structural relationships; tetracalcium phosphate; twinning.

$\mathrm{Ca}_{4}\left(\mathrm{PO}_{4}\right)_{2} \mathrm{O}$, tetracalcium diphosphate monoxide, crystallizes in the monoclinic unit cell $a=7.023(1), b=11.986(4), c=9.473$ (2) $\AA, \beta$ $=90.90(1)^{\circ}\left(\right.$ at $\left.25^{\circ} \mathrm{C}\right)$ in space group $P 2_{1}$ with $4\left[\mathrm{Ca}_{4}\left(\mathrm{PO}_{4}\right)_{2} \mathrm{O}\right]$ per cell. $3288 \mathrm{x}$-ray data were measured from a single crystal by $\theta-2 \theta$ scans using Mo $K \alpha$ radiation; 56 of these reflections were of "unobservable" intensity. The structure was solved by an application of direct phasing methods and subsequent calculation of an $E$ map. It was refined anisotropically by full-matrix least squares to $R_{w}(F)=0.036$, $R(F)=0 \cdot 037$. Allowance was made for isotropic secondary extinction but not for anomalous scattering or absorption. The dimensions of the unit cells of $\mathrm{Ca}_{4}\left(\mathrm{PO}_{4}\right)_{2} \mathrm{O}$ and $\mathrm{Ca}_{5}\left(\mathrm{PO}_{4}\right)_{3} \mathrm{OH}$ (hydroxyapatite), an idealized form of the major inorganic phase in the hyman body, are simply related. Although this 3 -dimensional relationship in the unit-cell shapes is not carried over into the details of the actual structures, $\mathrm{Ca}_{4}\left(\mathrm{PO}_{4}\right)_{2} \mathrm{O}$ does contain a layer which is similar to a layer in $\mathrm{Ca}_{5}\left(\mathrm{PO}_{4}\right)_{3} \mathrm{OH}$, and an epitaxic relationship between the two compounds is conceivable. $\mathrm{Ca}_{4}\left(\mathrm{PO}_{4}\right)_{2} \mathrm{O}$ is also related to the $\mathrm{K}_{3} \mathrm{Na}\left(\mathrm{SO}_{4}\right)_{2}$ (glaserite) structure. In this relationship the oxide ions are "extra" ions. One $\mathrm{Ca}$ ion in $\mathrm{Ca}_{4}\left(\mathrm{PO}_{4}\right)_{2} \mathrm{O}$ is weakly coordinated to a face of a $\mathrm{PO}_{4}$ group, a feature which has been previously observed for Ca only in a disordered cation site in $\beta-\mathrm{Ca}_{3}\left(\mathrm{PO}_{4}\right)_{2}$ The two crystallographically discrete oxide ions are surrounded by tetrahedra of $\mathrm{Ca}$ ions, with $\mathrm{Ca} \cdots \mathrm{O}$ distances in the range $2 \cdot 136$ (4) to $2 \cdot 277$ (3) $\AA$. Thus, the oxide ions do not lie in a channel formed by cations in the structure and $\mathrm{Ca}_{4}\left(\mathrm{PO}_{4}\right)_{2} \mathrm{O}$ cannot be considered to be an oxyapatite. The positions of the $\mathrm{P}$ atoms and the $\mathrm{Ca}$ and oxide ions lie close to those required by space group Pmcn. This explains the appreciable twinning exhibited by $\mathrm{Ca}_{4}\left(\mathrm{PO}_{4}\right)_{2} \mathrm{O}$. It also makes the existence of a higher-symmetry modification feasible.
Evans, A. G., Fracture mechanics determinations, (Proc. Conf. on Fracture Mechanics of Ceramics, Pennsylvania State Univ., University Park, Pa., July 11-13, 1973), Chapter in Fracture Mechanics of Ceramics, R. C. Bradt, D. P. H. Hasselman, and F. F. Lange, Eds., 1, 17-48 (Plenum Publ. Corp., New York, N.Y., 1974).

Key words: ceramics; failure prediction; fracture mechanics; materials development; techniques.

Techniques for the evaluation of fracture mechanics parameters are described. The selection of techniques for various ceramic applications is discussed, emphasizing the particular problems encountered with these measurements in ceramic systems. Finally, the application of fracture mechanics parameters to problems in both materials development and failure prediction in ceramic systems is described.

Fath, J. M., The sound of America today, Proc. 26th National Home Appliance Conference on Today's Realities, Boston, Mass., Nov. 29-Dec. 1, 1972, pp. 115-117 (Association of Home Appliance Manufacturers, Chicago, Ill., 1972).

Key words: home noise; noise sources; recreational; work.

An audio/visual presentation of various noise sources encountered in our daily lives at home, at work, and in recreational activities. The presentation was followed with a discussion of the general problems associated with noise in America today.

Fickett, F. R., Oxygen annealing of copper: A review, Mater. Sci. Eng. 14, No. 3, 199-210 (June 1974).

Key words: annealing; copper; oxidation; purification.

A useful technique for significantly increasing the low temperature electrical conductivity of copper is heating in the presence of a reduced pressure of oxygen. The same technique is sometimes used on dilute alloys to produce dispersion hardening by oxide particles. This paper reviews the literature on the oxidation process in copper. Particular emphasis is on oxidation to increase conductivity. A set of conditions for a purifying anneal are presented. A brief discussion of dispersion hardening by oxidation and of several chemisorption experiments is included.

Field, R. W., English, A. D., Tanaka, T., Harris, D. O., Jennings, D. A., Microwave optical double resonance spectroscopy with a cw dye laser: BaO $X^{1} \mathbf{\Sigma}$ and $A^{1}{ }^{1 \Sigma}, J$. Chem. Phys. 59, No. 5, 2191-2203 (Sept. 1, 1973).

Key words: cw dye laser; double resonance; microwave; spectroscopy.

A tunable, single frequency, continuous wave, dye laser has been used to optically pump various lines of the $\mathrm{BaO} A \mathrm{~A} \Sigma-X \quad 1 \Sigma$ electronic transition. Microwave optical double resonance (MODR) spectra are recorded as changes in the intensity of dye laser induced photoluminescence. Fourteen microwave rotational transitions in the $X^{1} \Sigma(\nu=0,1)$ and $A^{1} \Sigma(\nu=0-5)$ states of ${ }^{138} \mathrm{Ba}^{16} \mathrm{O}$ and one transition in the $A^{1} \Sigma(\nu=1)$ state of ${ }^{137} \mathrm{Ba}^{16} \mathrm{O}$ have been observed. Partially deperturbed rotational constants obtained for $\mathrm{BaO} A 1 \Sigma$ are $B(\nu)=$ $0.25832(2)-0.001070(5)(\nu+1 / 2) \mathrm{cm}^{-1}$. Two physical models are described which account for microwave optical double resonance effects in the strong (nonlinear) and weak (linear) optical pumping limits. Observed changes in photoluminescence polarization caused by excited state microwave transitions are predicted by a semiclassical transition dipole model. A three level steady state kinetic treatment of microwave optical double resonance indicates that the $\mathrm{BaO}$ MODR transitions reported in this paper are observed near the strong optical pumping limit. It is shown that for most allowed transitions in diatomic molecules a $100 \mathrm{~mW}$ single frequency, dye laser is sufficiently intense to significantly deplete rotational levels of the electronic ground state with respect to neighboring rotational levels and to cause the populations of the depleted ground state and optically pumped excited state levels to become comparable. 
Gadzuk, J. W., Chemisorption bond geometry determined by photoemission (Abstract), J. Vac. Sci. Technol. 11, No 1, 275 (Jan./Feb. 1974).

Key words: angular distributions; chemisorption; photoemission; photoionization; surfaces.

In this paper it is shown how a measurement of the angular distribution of electrons which are photoemitted from atoms chemisorbed on a metal surface can be used to determine the chemisorption bonding geometry.

Galejs, A., Kuyatt, C. E., Representation of focal properties of the equal-diameter two-tube electrostatic lens for computer calculations, J. Vac. Sci. Technol. 10, No. 6, 1114-1117 (Nov./Dec. 1973).

Key words: electron optics; electrostatic lenses; focal properties; lens optimization.

Previous calculations have given accurate first-order focal properties for the two-tube electrostatic lens at discrete voltage ratios. For computer optimization, calculations involving systems of two-tube lenses, one must be able to calculate the focal properties continuously over some arbitrary range of voltage ratios. Hence the data must be displayed in a continuous manner, and a method of interpolation is needed which yields functions having a high degree of smoothness. Special care must be taken to describe the lens behavior correctly near zero strength or for the voltage ratio approaching unity. A satisfactory solution to this problem has been achieved using cubic splines. The resulting functions of the focal properties are continuous and have continuous first and second derivatives. The total beam behavior, and hence the system design, is determined by the transfer matrix which is obtained from the focal properties. To achieve sufficient accuracy in the lens calculations over the entire range of required focal properties, the region near zero lens strength had to be treated separately.

Gallagher, A. C., York, G., A photoionization source of monoenergetic electrons, Rev. Sci. Instrum. 45, No. 5, 662-668 (May 1974).

Key words: monochromatic electrons; photoionization source.

A photoionization source of monoenergetic electrons is described and design criteria for such sources are discussed. The present design produces a beam of $\simeq 10^{-12}-10^{-13} \mathrm{~A}$ by photoionization of a metastable $\left({ }^{1} D_{2}\right)$ barium beam inside the cavity of a He-Cd laser operating at $3250 \AA$. The photoelectrons are produced with $17 \mathrm{MeV}$ kinetic energy and a calculated energy spread of $<1 \mathrm{MeV}$. Energy analysis is provided by measuring the width of the $11.08 \mathrm{eV}$ argon resonance. The observed width of this resonance has, to date, been limited to $\sim 6 \mathrm{MeV}$, but tests are reported which indicate that this width is largely due to Doppler spreading in the target atomic beam and potential gradients across the collision volume.

Haber, S., Shisha, O., Improper integrals, simple integrals, and numerical quadrature, J. Approximation Theory 11, No. 1, 115 (May 1974).

Key words: improper integrals; integration; numerical integration; quadrature; Riemann integrals.

The question of the convergence of numerical integration formulas (of Riemann sum type) to the improper Riemann integral $f_{\infty} f(x) d x$ is studied. A new integral over $[0, \infty)$, more restrictive than the improper Riemann integral but not absolutely convergent, is introduced. Necessary and sufficient conditions are found for a function to be integrable in the new sense; they are stated in terms of property of functions similar to the property of being of bounded variation. A convergence theorem for the numerical integration of such functions is given, and also weaker convergence theorems for the integration of improperly Riemann-integrable functions.
Haynes, W. M., Viscosity of saturated liquid methane, Physica 70, No. 2, 410-412 (Dec. 1973).

Key words: comparisons; graph; methane; saturated liquid; table; torsional crystal; viscosity.

The results of absolute measurements of the viscosity of saturated liquid methane using a torsionally vibrating quartz crystal are reported for temperatures from 95 to $190 \mathrm{~K}$. Comparisons are made with other data, all of which have been obtained with techniques different from that of the present work.

Hein, R. A., Cox, J. E., Blaugher, R. D., Waterstrat, R. M., van Reuth, E. C., Low-temperature annealing effects upon the superconducting properties of $\mathbf{V}_{3} \mathbf{A u}$, Physica 55, 523-533 (1971).

Key words: annealing; magnetic field; stoichiometry; superconductivity; transition temperature.

The superconducting transition temperature, $T_{0}$, and the initial slope of the upper critical magnetic field curve of $\mathrm{V}_{3} \mathrm{Au}$ have been measured as functions of low $\left(400-800{ }^{\circ} \mathrm{C}\right)$ temperature annealing. $T_{0}$ ranges from no superconductivity down to $0.015 \mathrm{~K}$ to a $T_{0}$ as high as $3.22 \mathrm{~K}$. X-ray diffractometer data indicated that all the samples employed in this study had the Al5 structure. Metallographic studies indicated the presence of a few percent of a second Au rich phase in these equilibrated samples. The $x$-ray data also indicated that the low-temperature anneals did change the degree of crystallographic long range order present in the samples and our data clearly indicate that $T_{0}$ increases quite markedly as the Bragg-Williams long-range order parameter approaches the value of unity. The magnitude of the initial slope of the critical magnetic field curve also increases with increase in $T_{0}$ (from $-22 \times 10^{3} \mathrm{Oe} / \mathrm{deg}$ to $-37 \times 10^{3} \mathrm{Oe} / \mathrm{deg}$ for $T_{0}=$ $0.89 \mathrm{~K}$ and $3.1 \mathrm{~K}$ respectively) with one notable exception, and that is the sample with the highest $T_{0}$ for which the slope has its smallest value, namely $-16 \times 10^{3} \mathrm{Oe} / \mathrm{deg}$.

Heinrich, K. F. J., Electron and ion probe microanalysis-physical bases, (Proc. Symp. on Microprobe Analysis as Applied to Cells and Tissues, Seattle, Wash., Apr. 29-May 2, 1973), Chapter in Microprobe Analysis as Applied to Cells and Tissues, pp. 75-87 (June 1974).

Key words: biological analysis; electron probe; ion probe; microprobe analysis; quantitation; soft tissue.

Both electron and ion probe analysis are tools for the detection and measurement of elements on a micrometer $(\mu \mathrm{m})$ scale. The physical bases of electron probe microanalysis are now reasonably well known, but the special conditions prevalent in the analysis of biological tissue present specific difficulties. New data evaluation procedures, such as the Monte-Carlo computation technique, may be useful to attack these problems.

The ion probe is a novel tool of great promise for the analysis of biological tissue since it combines shallow sampling with very high sensitivity and capability for the analysis of elements of low atomic number.

Heinrich, K. F. J., Rasberry, S. D., X-ray fluorescence analysis of high-temperature superalloys-calibration and standards, Chapter in Advances in X-Ray Analysis, C. L. Grant, C. S. Barrett, J. B. Newkirk, and C. O. Ruud, Eds. 17, 309-317 (Plenum Publ. Corp., New York, N.Y., June 1974).

Key words: calibration; empirical calibration; high-temperature superalloys; x-ray fluorescence; x-ray spectrochemical analysis.

The current experimental work extends our calibration concept of separating the effects of absorption and fluorescence to the high-temperature superalloys. The new calibration procedure produces calibration equations which are valid over wide ranges of composition - $\mathrm{a}$ feature which is useful in the analysis of high-temperature superalloys. For the specimens considered, the elements iron, nickel, chromium, cobalt and molybdenum can be present at levels greater 
than 10 percent; while tantalum, aluminum, titanium, manganese, sil. icon and vanadium may be present at levels between 1 and 6 percent. The calibration for this group of alloys has required, in the past, a large number of standards; the number is reduced by judicious application of the given correction equations. Analytical errors can be limited to 1 to 2 percent in the use of this method.

Hosteny, R. P., Hinds, A. R., Wahl, A. C., Krauss, M., MC SCF calculations on the lowest triplet state of $\mathrm{H}_{2} \mathrm{O}$, Chem. Phys. Letters 23, No. 1, 9-12 (Nov. 1, 1973).

Key words: electron impact; energy loss; energy surface; excitation energy; $\mathrm{H}_{2} \mathrm{O}$; repulsive curve; triplet state.

Recent electron impact work on $\mathrm{H}_{2} \mathrm{O}$ has shown a broad absorption peak near $4.5 \mathrm{eV}$ which has generally been attributed to the lowest triplet $\left({ }^{3} \mathrm{~B}_{1}\right)$ state of $\mathrm{H}_{2} \mathrm{O}$. However, the results of SCF and multiconfiguration SCF (MC SCF) calculations reported here indicate that the ${ }^{3} \mathrm{~B}_{1}$ state is unbound with respect to the dissociative asymptotes $\mathrm{H}\left({ }^{2} \mathrm{~S}\right)$ $+\mathrm{OH}\left({ }^{2} \Pi\right)$ and $\mathrm{O}\left({ }^{3} \mathrm{P}\right)+\mathrm{H}_{2}\left({ }^{1} \Sigma_{g}+\right)$, in disagreement with the experimental interpretation.

\section{Jacox, M. E., Milligan, D. E., Matrix isolation study of the vacuum ultraviolet photolysis of allene and methylacetylene vibrational and electronic spectra of the species $\mathbf{C}_{3}, \mathbf{C}_{3} \mathbf{H}, \mathbf{C}_{3} \mathbf{H}_{2}$, and $\mathbf{C}_{3} \mathbf{H}_{3}$, Chem. Phys. 4, 45-61 (1974).}

Key words: allene; $\mathrm{C}_{3} \mathrm{H}_{n}(n=0$ to 3 ); infrared spectrum; isotopic substitution; matrix isolation; methylacetylene; ultraviolet spectrum; vacuum-ultraviolet photolysis.

Upon hydrogen-discharge photolysis of normal or deuterium-substituted allene or methylacetylene in an argon or a nitrogen matrix at $14 \mathrm{~K}$, infrared absorptions of all of the $\mathrm{C}_{3} \mathrm{H}_{n}$ species with $n<4$ appear. A hydrogen-deformation fundamental of $\mathrm{C}_{3} \mathrm{H}_{2}$ has been identified in the far infrared. Infrared studies of the partially deuterium-substituted methylacetylenes indicate that extensive photoisomerization occurs. The observed products are consistent with those predicted using the previously postulated gas-phase photolysis mechanism. The ultraviolet spectrum of $\mathrm{C}_{3} \mathrm{H}_{3}$ corresponds closely with that characteristic of the gas-phase molecule. Comparison of the spectrum between 1900 and $4000 \AA$ of photolyzed methylacetylene with that of matrix-isolated graphite vapor has indicated that any new electronic transition of $\mathrm{C}_{3}$ in this region must be weak.

Kraft, R., Uniqueness and existence for the integral equation of interreflections, SIAM J. Math. Anal. 5, No. 2, 293-302 (Apr. 1974).

Key words: contractivity; existence of solutions; integral equations; interreflections; radiation transfer; uniqueness of solutions.

The integral equation of interreflections, determining radiant energy exchange in cavities, is shown to have a unique solution in the space on nonnegative functions defined over the cavity surface. The result is established by employing the contraction mapping principle.

Kuyatt, C. E., DiChio, D., Natali, S. V., Focal properties of the two-tube electrostatic lens for large voltage ratios, J. Vac. Sci. Technol. 10, No. 6, 1118-1119 (Nov./Dec. 1973).

Key words: electron trajectories; focal properties; P-Q curves; two-tube electrostatic lens; ultra-focal refraction.

Previous calculations of electron trajectories and first-order focal properties of the two-tube electrostatic lens have been extended to a voltage ratio of 1000 . Considerable ultrafocal refraction occurs in these strong lenses, with the result that near the highest voltage ratio studied the two focal points are both on the low-voltage side of the lens and nearly coincident. The results are presented in the form of a table and $P-Q$ (image-object) curves.
Kuyatt, C. E., DiChio, D., Natali, S. V., Third-order aberration coefficients of electron lenses. II, J. Vac. Sci. Technol. 10 , No. 6, 1124-1126 (Nov./Dec. 1973).

Key words: aberration integrals; asymptotic trajectories; electron lens; third-order aberration coefficients.

In the standard treatments of aberration coefficients of electron lenses, deviations from perfect imagery are expressed as power series of the ray coordinates in the object and aperture planes. The resulting aberration coefficients depend on the object and aperture positions, and a complete description of the aberrations of an electron lens would require a doubly infinite set of aberration coefficients for each voltage ratio of the lens. Hawkes has carried out a general treatment of the third-order aberrations of electron lenses which is independent of object and aperture positions. Six quantities are sufficient to specify the third-order aberration properties of an electron lens. We have derived equations for these six quantities in the form of integrals, involving derivatives of the axial potential no higher than the second, and using our previously calculated potentials have computed aberration coefficients for the two-tube electrostatic lens.

LaVilla, R. E., $M_{4,5}$ emission spectra from $\mathbf{G d}_{2} \mathrm{O}_{3}$ and $\mathbf{Y b}_{2} \mathbf{O}_{3}$, Phys. Rev. A 9, No. 5, 1801-1805 (May 1974).

Key words: $\mathrm{Gd}_{2} \mathrm{O}_{3}$; fluorescence spectra; $M_{4.5}$ emission spectra; resonance radiation; $\mathrm{Yb}_{2} \mathrm{O}_{3}$.

The $M_{4,5}$ emission spectra from $\mathrm{Gd}_{2} \mathrm{O}_{3}$ and $\mathrm{Yb}_{2} \mathrm{O}_{3}$ have been obtained in fluorescence on a double-crystal spectrometer. The profiles differ from the $M_{4,5}$ emission spectra excited by electron impact. These differences are due to resonance radiation and substantiate the interpretation given by Bonnelle and Karnatak. The $M \alpha$ emission line was found to lie above (in energy) the $M_{5}$-absorption resonance line $\mathrm{Yb}_{2} \mathrm{O}_{3}$, which is in contrast to $\mathrm{Gd}_{2} \mathrm{O}_{3}$ and general experience. It is suggested that this observation is a result of the discrete nature of the absorption lines. With the help of estimated binding energies for the final configurations $5 p^{5}{ }_{1 / 2,3 / 2} 4 f^{7}$, the photoelectron spectrum of $\mathrm{Gd}_{2} \mathrm{O}_{3}$ is discussed.

Levy, J., The optimal size of a storage facility, Nav. Res. Log. Quart. 21, No. 2, 319-326 (June 1974)

Key words: building design; inventory theory.

The appropriate size for a piece of fixed capital equipment (measured in units of capacity) depends on the anticipated demand for its services and on its cost. Using several models developed in the study of optimal inventory policy we derive the contribution to cost reduction that additional storage space makes under each of these models. Comparison of the sum of the discounted benefits (i.e., reduced operating cost) with construction costs for additional storage space then yields the optimal size of the storage facility.

Madey, T. E., Yates, J. T., Jr., Erickson, N. E., X-ray photoelectron spectroscopic study of the adsorption of $\mathrm{N}_{2}$ and $\mathrm{NO}$ on tungsten, Surface Sci. 43, 526-544 (1974).

Key words: chemical shifts; chemisorption; ESCA; nitric oxide; nitrogen; spectroscopy; x-ray photoelectron.

X-ray photoelectron spectroscopy (ESCA) has been used in a study of $\mathrm{N}_{2}$ and $\mathrm{NO}$ adsorbed on a polycrystalline tungsten ribbon. The sample was flash cleaned under ultrahigh vacuum conditions, and cooled to either 300 or $100 \mathrm{~K}$ for the adsorption studies. Large chemical shifts, as great as $8 \mathrm{eV}$, were observed between the $\mathrm{N}(\mathrm{ls})$ spectra associated with the weakly chemisorbed $\gamma$-nitrogen states and the strongly chemisorbed $\beta$-nitrogen states. Chemical shifts in both the $\mathrm{N}(\mathrm{ls})$ and $\mathrm{O}(\mathrm{ls})$ spectra suggest that $\mathrm{NO}$ is largely nondissociatively chemisorbed at $100 \mathrm{~K}$. In general, the binding energies of $\mathrm{N}(\mathrm{ls})$ and $\mathrm{O}(\mathrm{ls})$ electrons in the adsorbed layers are smaller than the binding energies for the same atoms in small gaseous molecules. In addition, the binding energies associated with the weakly-bound states of NO and $\mathrm{N}_{2}$ are invariably greater than the binding energies associated with strongly chemisorbed species. 
Milligan, D. E., Jacox, M. E., Spectra of free radicals and molecular ions produced by vacuum ultraviolet photolysis in low-temperature matrices, (Proc. Advanced Study Institute, NATO, Valmorin, Quebec, Canada, Aug. 5-17, 1973), Chapter in Chemical Spectroscopy and Photochemistry in the Vacuum-Ul. traviolet 8, Ser. C, 305-315 (D. Reidel Publ. Co., Boston, Mass., 1974).

Key words: free radicals; $\mathrm{HAr}_{n}{ }^{+}$; infrared spectrum; molecular ions; $\mathrm{NO}_{2}^{-}$; reaction of $\mathrm{OH}$ with $\mathrm{CO}$; ultraviolet spectrum; vacuum-ultraviolet photolysis of $\mathrm{HCN}$, of halogen cyanides, of $\mathrm{CH}_{4}$, of $\mathrm{CH}_{3} \mathrm{Cl}$, of $\mathrm{CH}_{3} \mathrm{OH}$, of $\mathrm{C}_{2} \mathrm{H}_{2}$, of $\mathrm{HCCl}_{3}$

The principles governing the stabilization of small free radicals and molecular ions in inert, rigid matrices will be reviewed. Emphasis will be placed on the strengths and limitations of the technique in obtaining information of concern to the photochemist. Examples will be drawn from studies of the vacuum-ultraviolet photolysis of $\mathrm{HCN}$, $\mathrm{CH}_{4}, \mathrm{CH}_{3} \mathrm{Cl}, \mathrm{CH}_{3} \mathrm{OH}, \mathrm{C}_{2} \mathrm{H}_{2}, \mathrm{NO}_{2}$, and $\mathrm{HCCl}_{3}$ in a matrix environment.

Newman, M., Modular quotient groups, Ill. J. Math. 18, No. 2, 265-274 (June 1974).

Key words: commutator subgroups; inclusion theorems; modular groups; quotient groups; solvability.

Let $\Gamma=S L(t, Z), \Gamma(n)$ the principal congruence subgroup of $\Gamma$ of level $n$. If $t>2$ it is shown that the commutator subgroup of $\Gamma(n) / \Gamma(n m)$ is $\Gamma(n \delta) / \Gamma(n m), \delta=(m, n)$. This implies that the number of 1-dimensional representations of $\Gamma(n) / \Gamma(n m)$ is $\delta^{t^{2}-1}$, and that $\Gamma(n) / \Gamma(n m)$ is solvable if and only if each prime dividing $m$ also divides $n$. Similar results are proved for $t=2$, by means of inclusion theorems proved in the paper. Another noteworthy result is that if $t>$ 2 , then the commutator subgroup of $\Gamma(n)$ is just $\Gamma\left(n^{2}\right)$.

Newman, M., Units in arithmetic progression in an algebraic number field, Proc. Am. Mathematical Soc. 43, No. 2, 266-268 (Apr. 1974).

Key words: algebraic number fields; units.

It is shown that a given algebraic number field of degree $n \geqq 4$ over the rationals can contain at most $n$ units in arithmetic progression, and that this bound is sharp.

Page, C. H., Definitions of electromagnetic field quantities, Amer. J. Phys. 42,490-496 (June 1974).

Key words: definitions; electromagnetism; fields.

A logically consistent set of definitions of the electromagnetic field quantities is extremely difficult to find in the literature. Most textbooks either evade the problem, or present definitions that are applicable only to special cases. A philosophy of this problem is presented, and a consistent system developed.

Page, C. H. Tetrahedral junction error contribution to a series-parallel four-terminal resistor, IEEE Trans. Instrum. Meas. IM-23, No. 1, 5-8 (Mar. 1974).

Key words: four-terminal; Hamon divider; resistance network; series-parallel; tetrahedral junction.

The errors of a series-parallel four-terminal resistor build-up box due to imperfections in the tetrahedral junctions are analyzed. It is shown how these errors can be made negligible by choosing orientations of the junctions.

Perloff, A., Quartz analysis by x-ray diffraction, Proc. Roundtable Discussion on Analytical Techniques for Quartz, Amer. Conf. Governmental Industrial Hygienists, Cincinnati, Ohio, Dec. 6-7, 1972, pp. 1b-6b (1973).

Key words: microanalysis by $\mathrm{x}$-ray diffraction; quartz dust.

Standard $x$-ray diffraction techniques can be readily used to mea- sure small quantities of respirable-sized quartz dust. Under idealized circumstances a practical lower limit of detection is $20 \mu \mathrm{g}$ of quartz within $\pm 5 \mu \mathrm{g}$. No significant difference between x-ray units of different manufacturers was observed.

Piermarini, G. J., Braun, A. B., Crystal and molecular structure of $\mathrm{CCI}_{4}$ III: A high pressure polymorph at $10 \mathrm{kbar}, J$. Chem. Phys. 58, No. 5, 1974-1982 (Mar. 1973).

Key words: carbon tetrachloride; crystal structure; diamondanvil cell; high pressure; polymorphism.

The crystal and molecular structure of a high pressure form of carbon tetrachloride $\left(\mathrm{CCl}_{4} \mathrm{III}\right)$ was determined at approximately $10 \mathrm{kbar}$ using a diamond-anvil beryllium pressure cell and a modified Buerger-type precession camera. $\mathrm{CCl}_{4}$ III crystallizes in the monoclinic system with a unit cell of the following dimensions: $a=$ $9.079 \pm 0.012 \AA, b=5.764 \pm 0.003 \AA, c=9.201 \pm 0.004 \AA$, and $\beta=$ $104.29 \pm 0.05^{\circ}$. The space group is $P 2_{1} / c$ with four molecules per unit cell. Observed infrared spectra indicate that the $\mathrm{CCl}_{4}$ molecule exhibits regular tetrahedral symmetry at $10 \mathrm{kbar}$. By using an approximation to the repulsion energy in a least-squares refinement procedure considering only nonbonded $\mathrm{Cl}-\mathrm{Cl}$ interactions, an approximate structure was obtained. Subsequent structure factor calculations using a grid-point sampling procedure yielded a final structure with a reliability factor of 9.56 percent. $\mathrm{CCl}_{4} \mathrm{III}$ is isostructural with $\mathrm{SnBr}_{4}$, and contains closest nonbonded Cl-Cl distances of $3.49 \AA$, sig. nificantly less than the normal Van der Waals separation of $3.6 \AA$. Taking four molecules per unit cell, the calculated density is $2.190 \mathrm{~g}$ $\mathrm{cm}^{-3}$. A more compact phase than $\mathrm{CCl}_{4} \mathrm{III}$ was predicted in the $\mathrm{CCl}_{4}$ system on the basis of packing efficiency and the predicted phase $\left(\mathrm{CCl}_{4} \mathrm{IV}\right)$ was subsequently verified by visual observation in microscopic studies at pressures in the $35-40$ kbar range and temperatures up to $500^{\circ} \mathrm{C}$.

Pyke, T. N., Jr., Blanc, R. P., Networking challenges: The user's viewpoint, (Proc. EDUCOM Fall Conf., Princeton, N.J., Oct. 9-11, 1973), Chapter 14 Transportability of Instructional Systems in Facts and Future, pp. 211-217 (EDUCOM, The Intercommunication Council, Princeton, N.J., 1974).

Key words: computer network; network access machine; network measurement machine; network user; resource sharing; user services.

A number of problems that impede the effective sharing of computer and information resources are identified and discussed. Taking examples from the use of present research and operational resource sharing networks, the difficulties associated with measuring and comparing performance of services provided, identifying and comparing costs to the end user, and determining the amount of effort required on the part of the user to successfully utilize a computer network are presented. Some approaches toward the solution of these problems are also discussed.

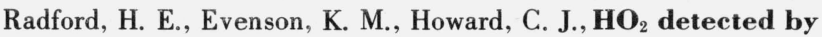
laser magnetic resonance, J. Chem. Phys. 60, No. 8, 3178-3183 (Apr. 15, 1974).

Key words: free radical; $\mathrm{HO}_{2}$; laser magnetic resonance.

Far-infrared absorption spectra of $\mathrm{HO}_{2}$ in the gas phase have been detected at six wavelengths of a water vapor laser magnetic resonance spectrometer. The identification of $\mathrm{HO}_{2}$ as the absorbing molecule is based on a partial analysis of the spectra and on a variety of different chemical methods used to produce the radical. Approximate values of rotational constants and spin doublet separations are derived from the spectra.

Righini, F., Cezairliyan, A., Pulse method of thermal diffusivity measurements (a review), High Temp.-High Pressures 5, 481501 (1973).

Key words: heat transfer; thermal conductivity; thermal dif- 
fusivity; thermophysical properties; transient techniques; transport properties.

The pulse (flash) method of measuring thermal diffusivity is reviewed. The basic theory of such measurements is presented and theoretical advances to account for departures from simplified as sumptions are discussed. The experimental systems for thermal diffusivity measurements employing the pulse method are described and a summary of investigations reported in the literature is given Emphasis is placed on the analysis of the accuracy of the method. Potentials of the technique for improved measurements at high temperatures are discussed.

Robertson, A. F., Effluent fire product - A crude approach to fire gas hazard assessment, Fire Technol., pp. 115-128 (May 1974).

Key words: effluent fire product; fire gas; fire hazard; gas hazard; hazard analysis; insulation; loss on ignition; potential heat.

A method is proposed for classifying the various factors influencing the life safety hazard posed during fires. Five fire hazard components are identified; these include oxygen deficiency, toxic combustion products, smoke particulates, hot gases and flame exposure. It is shown that the relative importance of these can be influenced by a number of hazard modifiers. These have been subdivided into three classes, those related to the material or product under consideration, those influenced by the fire location or degree of confinement and those associated with the people exposed.

It seems premature to try to evaluate in a quantitative way the influence of these many modifiers on the overall life hazard. However, it may serve a useful purpose in ranking materials or products with regard to the fire gas hazard to assume this is a function of the loss on ignition or the effluent fire product (EFP). An example of the usefulness of this concept is presented by a method for use of EFP in ranking insulation materials in such a manner that proper recognition is taken of their thermal properties.

A procedure making use of the potential heat test is proposed to permit avoidance of erroneously high value of EFP as a result of weight loss resulting from combined water and other inert components.

Roth, R. S., Parker, H. S., Brower, W. S., Minor, D., Alkali oxidetantalum oxide and alkali oxide-niobium oxide ionic conductors, NASA CR-134599, 60 pages (National Aeronautics and Space Administration, Washington, D.C., Apr. 1974).

Key words: alkali ions; ionic conductors; niobates; tantalates.

A search was made for new cationic conducting phases in alkalitantalate and niobate systems. The phase equilibrium diagrams were constructed for the six binary systems $\mathrm{Nb}_{2} \mathrm{O}_{5}-\mathrm{LiNbO}_{3}, \mathrm{Nb}_{2} \mathrm{O}_{5^{-}}$ $\mathrm{NaNbO}_{3}, \mathrm{Nb}_{2} \mathrm{O}_{5}-\mathrm{KNbO}_{3}, \mathrm{Ta}_{2} \mathrm{O}_{5} \mathrm{LiTaO}_{3}, \mathrm{Ta}_{2} \mathrm{O}_{5}-\mathrm{NaTaO}_{3}$ and $\mathrm{Ta}_{2} \mathrm{O}_{5^{-}}$ $\mathrm{KTaO}_{3}$. Various other binary and ternary systems were also examined. Pellets of nineteen phases were evaluated (by the sponsoring agency) by dielectric loss measurements. Attempts were made to grow large crystals of eight different phases. The system $\mathrm{Ta}_{2} \mathrm{O}_{5}$ $\mathrm{KTaO}_{3}$ contains at least three phases which showed peaks in dielectric loss vs. temperature. All three contain structures related to the tungsten bronzes with alkali ions in nonstoichiometric crystallographic positions.

Ryan, J. V., Standards for textiles in the U.S.A., Gottleib Duttweiler Institutes J. 2, No. 5, 35-41 (May 1971); Polymer News 1, Nos. 6-7, 10-18 (1973).

Key words: beds; carpets; Child Protection Act; fabrics; flammability; Flammable Fabrics Act; Hill-Burton Act.

Mandatory standards for flame-resistant textiles, or related materials, are authorized under the Flammable Fabrics Act (Department of Commerce), the Child Protection Act amendments to the Federal
Hazardous Substances Act (Department of Health, Education, and Welfare), the Hill-Burton and Medicare Acts (Department of Health, Education, and Welfare), the National Highway Safety Act (Department of Transportation), and the basic Acts of the U.S. Coast Guard and the Federal Aviation Administration. Of these Statutes, the Flammable Fabrics Act is the most comprehensive, including within its scope all wearing apparel and interior furnishings for homes, offices, and places of assembly or accommodation. Standards are authorized also under State and local laws, particularly those relating to building or fire codes. Flammability requirements in purchase specifications have the force of law when made part of a contract.

Standards or proposed standards have been published for wearing apparel, carpets and rugs, small carpets and rugs, toys, floor coverings in hospitals and long term care facilities, merchant ships, aircraft cabin liners and furnishings. and motor vehicles. Building and fire codes usually set requirements only for textile furnishings in places of assembly. Purchase specifications rarely include flammability requirements except when the intended use is regulated by statutory requirements.

Schweitzer, W. G., Jr., Kessler, E. G., Jr., Deslattes, R. D., Layer, H. P., Whetstone, J. R., Description, performance, and wavelengths of iodine stabilized lasers, Appl. Opt. 12, No. 12, 2927-2938 (Dec. 1973).

Key words: iodine stabilized lasers; krypton; pressure broadening; pressure shifts; saturated absorption; wavelengths.

A description is given of lasers stabilized to components of the ${ }^{129} \mathrm{I}_{2}$ spectrum in the region of the $633-\mathrm{nm}$ laser lines for ${ }^{3} \mathrm{He}^{-20} \mathrm{Ne}$ and ${ }^{3 \mathrm{He}}$ ${ }^{22} \mathrm{Ne}$. Relationships between operational characteristics such as power output, peak size, and peak width are shown, along with their relationships to some of the controllable parameters such as excitation level, iodine absorption, and iodine pressure. We found an iodine pressure broadening of about $13 \mathrm{MHz}$ /torr with a 2.6- $\mathrm{MHz}$ zero-pressure intercept. The frequency shift associated with iodine pressure is roughlv $2 \times 10^{-9} \nu /$ torr to the red. Power broadening and power shifts are small, about a 10 percent increase in width and about $2 \times$ $10^{-11} \nu$ variation in frequency for a fivefold to sixfold increase in power. These lasers exhibit a frequency stability for 10 -sec sampling time of about $2 \times 10^{-12} \nu$ and a resetability of about $1 \times 10^{-10} \nu$. The absolute vacuum wavelength for one iodine component has been measured against the ${ }^{86} \mathrm{Kr}$ standard $-{ }^{3} \mathrm{He}^{-20} \mathrm{Ne}:{ }^{129} \mathrm{I}_{2}, \quad k \quad \lambda=632$ $991.2670 \pm 0.0009 \mathrm{pm}$. The wavelengths of several other iodine components have been determined by measuring the frequency difference between them and the ${ }^{129} \mathrm{I}_{2}, k$ component. Among these are ${ }^{3} \mathrm{He}^{22}{ }^{22}:{ }^{129} \mathrm{I}_{2}, B \quad \lambda=632990.0742 \pm 0.0009 \mathrm{pm}$ : and ${ }^{3} \mathrm{He}^{20}{ }^{20} \mathrm{Ne}^{127} \mathrm{I}_{2}, i$ $\lambda=632991.3954 \pm 0.0009 \mathrm{pm}$. These results were obtained using the Rowley-Hamon model for asymmetry in the krypton line and assume that the defined value for the standard is associated with the center of gravity of the line profile. The indicated uncertainties are statistical. No allowance has been included for imperfect realization of the krypton standard or for uncertainty in the asymmetry model.

Stephenson, J. C., Mosburg, E. R., Jr., Vibranonal energy transfer in CO from 100 to $300 \mathrm{~K}$, J. Chem. Phys. 60, No. 9, 3562-3566 (May 1, 1974).

Key words: carbon monoxide; $\mathrm{CO}_{2}$ lasers; combustion; optical pumping of molecules; vibrational relaxation.

The laser fluorescence method, whereby $\mathrm{CO}$ molecules are optically pumped from the vibrational level $v=0$ to the $v=1$ state by frequency-doubled pulses from a $\mathrm{CO}_{2}$ laser, has been used to determine vibrational energy transfer rate coefficients for $\mathrm{CO}$. Rates for the $V \cdot V$ exchange processes $\mathrm{CO}(0)+\mathrm{N}_{2}(1) \rightarrow \mathrm{CO}(1)+\mathrm{N}_{2}(0)$ and $\mathrm{CO}(1)$ $+\mathrm{CO}(1) \rightarrow \mathrm{CO}(0)+\mathrm{CO}(2)$, and for the deactivation of $\mathrm{CO}(1)$ by $\mathrm{H}_{2}$ have been measured in the range $100 \mathrm{~K} \leqslant T \leqslant 300 \mathrm{~K}$. The probability of energy transfer from $\mathrm{N}_{2}$ to $\mathrm{CO}$ decreases slightly as $T$ decreases in this range, while the probability of the CO-CO $V-V$ process is approximately proportional to $T^{-1}$. Rate coefficients were also measured at 
$T=297 \mathrm{~K}$ for the deactivation of $\mathrm{CO}(1)$ by the polyatomic molecules $\mathrm{CH}_{4}, \mathrm{C}_{2} \mathrm{H}_{4}, \mathrm{C}_{2} \mathrm{H}_{6 n} \mathrm{HCOOH}, \mathrm{CH}_{3} \mathrm{COOH}, \mathrm{CH}_{3} \mathrm{CHO}, \mathrm{CH}_{3} \mathrm{OH}, \mathrm{C}_{2} \mathrm{H}_{5} \mathrm{OH}$, $\mathrm{H}_{2} \mathrm{O}, \mathrm{D}_{2} \mathrm{O}, \mathrm{H}_{2} \mathrm{~S}$, and $\mathrm{C}_{4} \mathrm{H}_{10}$.

Stiehler, R. D., Standards and standardization, Am. Soc. Testing Mater. Spec. Tech. Publ. 553, 87-103 (1974).

Key words: interlaboratory testing; international standards; standardization; standards.

Standards are practices established by authority, custom, or common consent. The practices embrace all activities of society including social, religious educational, and technical practices. This paper deals with technical practices embodied in national or international engineering standards. A good engineering standard should: (1) stimulate competition and not restrict trade; (2) prescribe practices which conserve natural resources; (3) be abreast of technology and not be a deterrent to desirable change arising from new knowledge, new capabilities, or new environment; (4) be concise, explicit, and limited to essential provisions and requirements; and (5) be effective in achieving its purpose.

Due to the rapid increase in the number of standards both domestically and internationally, there is a movement to control proliferation through the development and use of international standards, primarily under the aegis of the International Organization for Standardization (ISO) and the International Electrotechnical Commission (IEC). Standards developed by ISO and IEC have now become sufficient in number to be a significant factor in international trade.

Standards development has varied considerably from one industry to another, and U.S. participation in ISO and IEC has also varied from industry to industry. ISO Technical Committee 45 on Rubber and Rubber Products has been among the ten most active committees, and U.S. participation has been exceptionally effective in it. Nearly 80 percent of the 102 standards developed by ISO/TC 45 through 1972 are in accord with ASTM Standards.

Recently, there has been a growing interest in standards for consumer products, both nationally and internationally. Eight of the 20 ISO committees most recently established deal with consumer products. There has also been a growing interest in ascertaining the ability of laboratories to obtain consistent results using standard methods, both nationally and internationally. The Standard Reference Materials issued by NBS and the NBS interlaboratory programs for testing were established for this purpose. Laboratory performance, international standardization, and the development of standards for consumer products are likely to become increasingly important in future standardization efforts.

Sugar, J., Revised ionization energies of the neutral actinides, J. Chem. Phys. 60, No. 10, 4103 (May 15, 1974).

Key words: actinium; americium; berkelium; californium; curium; einsteinium; fermium; ionization energy; mendelevium; neptunium; nobelium; plutonium; protactinium; thorium; uranium.

Revised values for the ionization energies of the neutral actinide atoms based on new experimental data are given.

Swartzendruber, L. J., Bennett, L. H., Schoefer, E. A., DeLong, W. T., Campbell, H. C., Mössbauer-effect examination of ferrite in stainless steel welds and castings, Weld. J. 39, No. 1, 1-S12-S (Jan. 1974).

Key words: backscattering; casting; ferrite; Mössbauer; stainless steel; welding.

The differences between wholly austenitic, single phase stainless steels and those with two phase, partially ferritic structures have assumed commercial importance in recent years, but full utilization of the benefits to be derived from such two phase materials has been hampered by difficulties in establishing their exact ferrite contents.
The Mössbauer-effect scattering method measures the relative amounts of the austenite and ferrite phases on the basis of their mag netic properties in a way which is relatively independent of the shape, size and orientation of the ferrite particles.

Taylor, P. O., Dolder, K. T., Kauppila, W. E., Dunn, G. H., Measurement of spiraling in a magnetically confined electron beam for use in collision studies, Rev. Sci. Instrum. 45, No. 4, 538-544 (Apr. 1974).

Key words: electron gun; measurement of spiraling; spiraling.

A method is described to directly measure mean spiral diameter in a magnetically confined electron beam. In collision experiments, spiraling affects polarization measurements and effective path length assessment; and in experiments using colliding beams, the collision energy or energy spread can be significantly altered. The technique described here allows experimental correction for these effects. Magnitudes of transverse velocities from various causes leading to spiraling are estimated on the basis of models. A gun designed for use in crossed beam electron-ion excitation experiments is described, and results of tests on spiraling and space charge effects for this gun are given. The tests generally indicate the modeling to be correct. Judicious choice of operating conditions led to path length corrections as small as $4 \pm 2$ percent at $3 \mathrm{eV}$, decreasing to $0.25 \pm 0.2$ percent at 200 $\mathrm{eV}$.

Treu, S., Techniques and tools for improving the interactive system interface, (Proc. Interactive Bibliographic Systems, Gaithersburg, Md., Oct. 4-5, 1971), U.S. Atomic Energy Commission Symp. Series 28, pp. 32-38 (Apr. 1973).

Key words: data collection techniques; interactive system interface; retrieval systems; user-system interface.

This is an account of a brief talk presented to the User Interface Session of the Forum on Interactive Bibliographic Systems. Consistent with the planned panel format of that Session, it is not a formally prepared paper. After some assertions about the need for considering the user and his system to be a team and about having to recognize user behavior and satisfaction in assessment of team performance, the use of more unobtrusive techniques for pertinent data collection is advocated. Two tools for enabling these techniques are described: a dialogue monitor which can record the entire two-way message stream and certain related timing data, and a user stimulation system which can actively manipulate the interaction while collecting data on resulting user satisfaction.

Tsai, D. H., MacDonald, R. A., Heat pulse propagation in a crystal: A molecular dynamical calculation,Solid State Commun. 14, No. 11, 1269-1273 (1974).

Key words: anharmonicity; crystal; heat pulse; lattice; molecular dynamics; second sound; stress wave; temperature wave; thermal relaxation.

The propagation of a heat pulse into a perfect bcc crystal is studied by means of molecular dynamical calculations. We observe second sound waves associated with the heat pulse as well as with longitudinal and transverse elastic pulses. Our results explain a number of features observed in second sound experiments and suggest that second sound is a phenomenon of general occurrence.

Tsang, W., Recalculation of data on the thermal decomposition of 1,1-difluoroethane and 1,1,1-trifluoroethane, Int. J. Chem. Kinet. V, 643-649 (1973).

Key words: elimination; fluoroethane; kinetics; single pulse shock tube; thermal decomposition; 1,1-difluoroethane; 1,1,1trifluoroethane.

Disagreements in rate constants and parameters between published results on the decomposition of 1,1-difluoroethane and 1,1,1-trifluoroethane are shown to originate from incorrect specifica- 
tion and setting of reaction conditions in one of the studies. When corrected, applicable results are in excellent agreement.

Tsang, W., Thermal decomposition of 1,1,2,2-tetramethylcyclopropane in a single-pulse shock tube, Int. J. Chem. Kinet. V,651-662 (1973).

Key words: cyclohexene; decomposition; decyclization; shock tube; 2,4-dimethylpentene-2; 1,1,2,2-tetramethylcyclopropane.

1,1,2,2-Tetramethylcyclopropane (TTMC) has been decomposed in a single-pulse shock tube. The main reaction process is

$$
\begin{aligned}
\text { TTMC } & \stackrel{k_{1}}{\rightarrow} 2,4 \text {-dimethylpentene-2(2,4 DMP-2) } \stackrel{k_{2}}{\rightarrow} \\
& \left(\mathrm{CH}_{3}\right)_{2} \mathrm{C}-\mathrm{CH}-\mathrm{CH}\left(\mathrm{CH}_{3}\right)+\mathrm{CH}_{3}
\end{aligned}
$$

Side reactions are unimportant. From comparative rate experiments (with cyclohexene decomposition as standard) the rate expression for these reactions are

$$
\begin{aligned}
& k_{1}=10^{14.82} \exp (-31,320 / \mathrm{T}) \mathrm{sec}^{1} \\
& k_{2} \sim 10^{16.0} \exp (-35,050 / T) \mathrm{sec}^{1}
\end{aligned}
$$

These numbers are consistent with a "best" value for cyclohexene decomposition of

$$
k\left(c \mathrm{C}_{6} \mathrm{H}_{10} \rightarrow 1,3-\mathrm{C}_{4} \mathrm{H}_{6}+\mathrm{C}_{2} \mathrm{H}_{4}\right)=10^{15.15} \exp (33,500 / \mathrm{T}) \sec ^{1}
$$

Velapoldi, R. A., Reisfeld, R., Boehm, L., Quantum efficiencies and transition probabilities of $\mathrm{Eu}^{3+}$ in silicate glasses, Phys. Chem. Glasses 14, No. 6, 101-106 (Dec. 1973).

Key words: europium; fluorescence; lifetimes; luminescence; nonradiative rates; oscillator strengths; quantum efficiencies; radiative rates; rare earths; silicate glasses.

Absorption, excitation, and emission spectra of $\mathrm{Eu}(\mathrm{III})$ in silicate glasses have been measured. The oscillator strengths for transitions from the populated ${ }^{7} F$ multiplet have been calculated and compared with those in other matrices. Quantum efficiencies were determined by comparative and lifetime measurements. Percentage quantum efficiencies for the ${ }^{5} D_{i} \rightarrow{ }^{5} D_{0}$ transitions and radiative and nonradiative rate constants were calculated.

Wagman, D. D., Jobe, T. L., Domalski, E. S., Schumm, R. H., Temperatures, pressures, and heats of transition, fusion and vaporization, Chapter $4 \mathrm{j}$ in American Institute of Physics Handbook, Third Edition, D. E. Gray, Ed., pages 4-222-4-261 (McGraw-Hill Book Co., New York, N.Y. 1972).

Key words: fusion heat; fusion temperature; transition heat; transition temperature; vaporization heat; vaporization temperature.

Summary of values of temperatures, pressures and heats of phase change for a selected set of inorganic and organic substances. Data for over 500 compounds are tabulated, including all elements for which thermodynamic information is available, halides, oxides, and some sulfates, nitrates, etc.

Waterstrat, R. M., van Reuth, E. C., Effects of compositional variations on the atomic ordering in Al5 phases, (Proc. 3d Bolton Landing Conf. on Ordered Alloys, Lake George, N.Y., Sept. 8, 1969), Chapter in Ordered Alloys, Structural Application and Physical Metallurgy, pp. 95-110 (Claitor's Publ. Div., Baton Rouge, La., 1970).

Key words: A-elements; B-elements; A-site atoms; band structure; d-electron; electron-compound; wave-functions.

Binary Al5 phases containing only transition elements have been found to possess composition ranges which shift in a regular manner consistent with periodic table positions. This is suggestive of the socalled "electron-compound" behavior previously noted for the sigma phases and other complex structures. It has been shown that devia: tions from the "ideal" $\left(A_{3} B\right)$ composition are accomplished by direct substitution of A-elements and B-elements rather than by vacancy formation. The degree of long-range atomic ordering decreases as one selects elements closer to the manganese column in the periodic table. This effect may be related to the extent of overlapping for d-electron wave-functions particularly along the chains of A-site atoms and is consistent with the band structure model proposed by Labbé and Friedel.

Watson, R. E., Bennett, L. H., Charge transfer in alloys: The blind men and the elephant, (Proc. Twin Symp. sponsored by the Committee on Alloy Phases of the Inst. of Metals, Univ. of Pennsylvania, Philadelphia, May 1973), Chapter in Charge Transfer/Electronic Structure of Alloys, L. H. Bennett and R. H. Willens, Eds., pp. 1-21 (Published by the Metallurgical Society of AIME, Inc., New York, N.Y., 1974).

Key words: alloys; atomic volume; charge transfer; chemical bonding; internal conversion; isomer shift.

This paper attempts to provide an introduction to the concepts underlying much of the discussion in the papers presented at the Symposium on Charge Transfer in Alloys. It also concentrates on two related methods of obtaining charge transfer information in alloys which are not covered elsewhere in the Symposium, namely, the Môssbauer isomer shift and internal conversion experiments.

Weinstein, B. A., Piermarini, G. J., First and second order Raman scattering in GaP to 128 kbar, Physics Lett. 48A, No. 1, 14-16 (May 20, 1974).

Key words: diamond-anvil cell; gallium phosphide; Raman scattering.

One- and two-phonon room temperature Raman spectra of $\mathrm{GaP}$ were measured to $128 \mathrm{kbar}$ using a diamond-anvil pressure cell. Linear and quadratic pressure coefficients were determined for phonons at $\Gamma, \mathrm{L},(\mathrm{X} \rightarrow \mathrm{K})$, and $\Sigma$. The results suggest possible "soft" mode behavior for TA $(\mathrm{L})$ and $\mathrm{TA}(\mathrm{X} \rightarrow \mathrm{K})$ phonons. 